\title{
Facilitation and Depression at Different Branches of the Same Motor Axon: Evidence for Presynaptic Differences in Release
}

\author{
Paul S. Katz, ${ }^{1}$ Mark D. Kirk, ${ }^{2}$ and C. K. Govind ${ }^{3}$ \\ ${ }^{1}$ Department of Neurobiology and Anatomy, University of Texas Medical School, Houston, Texas 77225, ${ }^{2}$ Division of \\ Biological Sciences, University of Missouri-Columbia, Columbia, Missouri 65211, and ${ }^{3}$ Life Sciences Division, Scarborough \\ College, University of Toronto, Scarborough, Ontario M1C 1A4, Canada
}

This study provides evidence that a neuron can exhibit differences in activity-dependent transmitter release at two synaptic sites due to variations in the properties of its presynaptic terminals. Two muscles in the stomatogastric system of the lobster Homarus americanus are innervated by a single motor neuron but respond differently to that motor neuron's input, resulting in two different movements evoked by one motor neuron. During continued motor neuron stimulation, the gm 8 muscle contracts slowly and maintains contraction, while the gm9 muscle contracts rapidly and then relaxes. These different muscle responses can be accounted for, in large part, by the properties of the respective neuromuscular synapses: the excitatory junctional potentials recorded in $\mathbf{g m} 8$ are initially small but summate and facilitate with repeated stimulation, while those in $\mathrm{gm} 9$ are initially large but depress with repeated stimulation. Presynaptic differences in neurotransmitter release contribute strongly to the divergent responses; reduction of the excitatory junction potential amplitude by partial postsynaptic receptor blockade or by desensitization does not change the amount of depression at gm9. However, reduction of neurotransmitter release with low-Ca ${ }^{2+}$, high- $\mathrm{Mg}^{2+}$ saline removes gm9 synaptic depression and reveals that both neuromuscular junctions exhibit frequency-dependent homosynaptic facilitation. Postsynaptic differences in muscle input resistance and muscle composition may enhance the effects of the divergent release properties, but are not responsible for the activity-dependent changes. Ultrastructural features of the nerve terminals on the two muscles are consistent with the differential output of the terminals; the synapses on gm9 are larger and have more presynaptic dense bars than their counterparts on gm8. These data suggest that the basis for the differences in transmitter release between the two

\footnotetext{
Received Oct. 9, 1992; revised Jan. 28, 1993; accepted Feb. 1, 1993.

This work was supported by the following grants and fellowships: a Grass Foundation fellowship to P.S.K., an NIH grant to M.D.K., and a grant from NSERC Canada to C.K.G. We thank Dr. Barbara Beltz and Mike Syslo for giving us larval animals. We thank Dr. Irwin Levitan for the apamin and charybdotoxin, and Dr. Ronald Harris-Warrick for help and support and allowing us to use lab space for this project. We especially thank Joanne Pearce and Christine Gee for their electron microscopic work and their help in animal maintenance, and Tara Vicknair for her help with illustrations. We thank Dr. Lise Eliot and Dr. Sarah Pallas for their helpful comments on the manuscript, and Dr. William Frost for his advice on the computer simulations.

Correspondence should be addressed to Paul S. Katz, University of Texas Medical School, Department of Neurobiology and Anatomy, P.O. Box 20708, Houston. TX 77225 .

Copyright (C) 1993 Society for Neuroscience $0270-6474 / 93 / 133075-15 \$ 05.00 / 0$
}

muscles may be a higher density of release sites in the gm9 synapses that leads to a higher output of neurotransmitter, rapid depletion of transmitter stores, and synaptic depression.

[Key words: activity dependence, synaptic facilitation, synaptic depression, lobster, electron microscopy, stomatogastric system]

Neurons often can affect multiple postsynaptic targets differentially. In some cases this is due to properties of the postsynaptic receptors that mediate different responses to the same neurotransmitter. For example, motor neurons of the stomatogastric ganglion release the same neurotransmitter within the ganglion and at the muscles, yet the ganglionic synapses are exclusively inhibitory due to inhibitory receptors while the neuromuscular synapses are purely excitatory due to excitatory receptors (Marder, 1987). It is also possible that differences between the individual presynaptic terminals can result in differential transmitter release. We have evidence to suggest that a presynaptic mechanism is responsible for differences in activity-dependent facilitation and depression between nerve terminals of a single motor neuron.

Activity-dependent facilitation and depression of synaptic responses have important behavioral implications for the functioning of nervous systems (Zucker, 1989). Synaptic facilitation, which is a progressive increase in the amplitude of postsynaptic potentials (PSPs) with repeated stimulation, is involved in amplifying signals that arrive in rapid succession. Synaptic depression, a progressive decrease in the amplitude of PSPs, is often associated with sensory and neuromuscular systems that mediate escape responses that habituate (Thies, 1965; Zucker, 1972; Kusano and Landau, 1975; Czternasty et al., 1980; Byrne, 1982; Wine and Krasne, 1982).

The mechanisms underlying these types of synaptic plasticities have been investigated in a variety of preparations (Thies, 1965; Castellucci and Kandel, 1974; Schlapfer et al., 1974; Atwood and Wojtowicz, 1986; Sarrazin, 1987; Zucker, 1989; Larkman et al., 1991). In some cases, synaptic facilitation appears to be caused by an increase in the residual calcium in the presynaptic nerve terminal during high-frequency stimulation (Katz and Miledi, 1968; Zucker, 1989; Swandulla et al., 1991). A likely mechanism underlying many forms of synaptic depression is depletion of neurotransmitter (Liley and North, 1953; Thies, 1965; Betz, 1970; Zucker, 1989). Another presynaptic mechanism for depression that has been proposed is a frequencydependent conduction failure at axon terminal branch points (Hatt and Smith, 1976). Postsynaptic mechanisms such as re- 


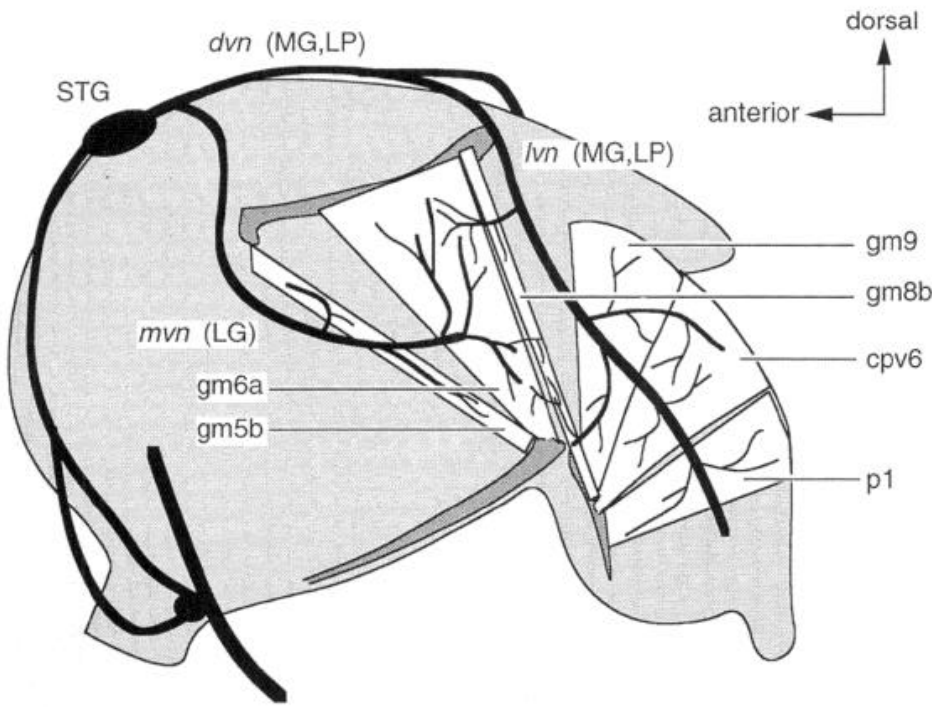

Figure 1. Schematic view of the foregut showing the locations of the muscles and nerves investigated. The stomatogastric ganglion (STG) contains the cell bodies of the motor neurons whose axons exit the ganglion posteriorly through the dorsal ventricular nerve $(d v n)$. The medial gastric $(M G)$ motor neuron axon runs in the lateral ventricular nerve ( $l v n)$ along with the axon of the lateral pyloric $(L P)$ motor neuron. $M G$ innervates the $g m 8 b$ and $g m 9$ muscles, as well as fibers in the posterior portion of the gm6a and the anterior part of the cpv6 muscles. $L P$ innervates the $c p v 6$ and $p 1$ muscles. The axon of the lateral gastric $(L G)$ motor neuron projects through the medial ventricular nerve $(m v n)$ to innervate muscles $g m 5 b, g m 6 a$, and sometimes $g m 8 b$.

ceptor desensitization have also been proposed (Gardner and Kandel, 1977).

In crustaceans, the neuromuscular synapses made by a single motor neuron onto different fibers of the same muscle can vary in transmitter release and the extent of facilitation or depression (Atwood, 1967, 1976; Bittner, 1968; Bryan and Atwood, 1981; Atwood and Wojtowicz, 1986). This regional specialization in output is a hallmark of crustacean synapses, allowing fine control of muscle contraction with a small number of motor neurons. While crustacean neuromuscular synapses often differ in the magnitude of facilitation or depression, to our knowledge there are no reported examples of a single motor neuron that makes both synapses that facilitate and synapses that depress.

Occasionally, a single excitatory crustacean motor neuron may innervate two separate muscles with different functions (e.g., the stretcher and opener muscles in decapod limbs; Wiersma, 1961). To achieve functional independence, each muscle receives exclusive inhibition that is very effective at blocking out the action of the excitor motor neuron. Sharing of excitatory motor neurons is common for the striated muscles in the foregut of decapod crustaceans (Maynard and Dando, 1974; Govind et al., 1975; Govind and Lingle, 1987). However, there is no inhibitory innervation to these muscles. Thus, any functional separation of the muscles within a motor unit must be achieved via pre- and postsynaptic mechanisms of the excitatory neuromuscular innervation.

We have found two muscles in the foregut of the lobster Homarus americanus that are innervated by a common motor neuron and that have opposite activity-dependent responses to the motor neuron's input. These two muscles play different roles in the production of foregut motor behavior determined by their divergent responses to input from the motor neuron they have in common. We have investigated the synaptic mechanisms responsible for the functional differences between the two muscles.

\section{Materials and Methods}

Dissection and physiology. Adult lobsters, Homarus americanus, were obtained from local seafood suppliers. Lobsters in the larval stages 13 and postlarval stages 4-6 (Herrick, 1895) were obtained from Mike Syslo (Massachusetts State Lobster Hatchery on Martha's Vineyard) and as a gift from Dr. Barbara Beltz (Wellesley College, Wellesley, MA). Larval lobsters were reared at the Marine Biological Laboratory, Woods Hole, MA, in running seawater at ambient temperature. The three larval stages were reared communally, but at the molt to the fourth stage, marking the beginning of juvenile development, the lobsters were placed in individual trays until a year old (Lang, 1975) and then in individual compartments in a large tank. The lobster colony, therefore, comprised many stages of juveniles ranging in carapace length from $<5 \mathrm{~mm}$ to 80 $\mathrm{mm}$. Most experiments were performed on juvenile animals (stages 816) with carapace lengths between 2 and $4 \mathrm{~cm}$. Juveniles at stages 4-6 were used for experiments in which low-calcium saline was used. Unless otherwise noted, data shown are from juvenile animals after stage 8 . Data for this article were collected from a total of 40 animals.

For physiological recording, the dorsal carapace was removed and the foregut with its associated nerves and muscles was dissected free by cutting the extrinsic muscle attachments. The foregut was split along its ventral surface and pinned, dorsal side up, in a Sylgard-lined petri dish.

The medial gastric (MG) motor neuron has its cell body in the stomatogastric ganglion. It projects a single axon through the dorsal ventricular nerve $(d v n)$, which then bifurcates and travels through the bilaterally paired lateral ventricular nerves (lvn) (Fig. 1). MG innervates two bilaterally symmetric muscle groups, gm8b and gm9 (Maynard and Dando, 1974). The gm9 muscle is composed of three groups (gm9a, gm9b, and gm9c) that differ slightly in their origin and insertion points (Maynard and Dando, 1974). We will refer to all three groups together as gm9 since there is no apparent difference in their innervation or their synaptic properties. To simplify the notation for this article, the gm $8 \mathrm{~b}$ muscle will be referred to simply as gm8; in this species there is no gm8a muscle (Maynard and Dando, 1974).

The MG axon was stimulated extracellularly on the $d v n$ or $l v n$ using a fire-polished glass suction electrode. Intracellular recordings were made in both gm 8 and gm 9 using glass micropipettes filled with $3 \mathrm{M} \mathrm{KCl}$ and having resistances of 5-10 M $\Omega$ for large animals and $10-20 \mathrm{M} \Omega$ for small animals. Intracellular stimulation of the MG soma in the stomatogastric ganglion confirmed that this motor neuron innervates both muscles (data not shown). Extracellular stimulation can be used to excite MG exclusively because no other motor axons in the $l v n$ innervate both gm 8 and gm9 (Maynard and Dando, 1974). The lateral pyloric (LP) motor neuron also runs in the $l v n$ and innervates a few muscle fibers along the posterior margin of gm 9 (see below); therefore, all recordings presented here were made from fibers in the anterior sections of gm 9 .

For the mapping studies, two intracellular electrodes were placed in different muscle fibers. Motor axons were then recruited in the $d v n$ or $l v n$ by gradually increasing the stimulus strength. Excitatory junction potentials (EJPs) evoked in two muscle fibers by a common motor neuron had the same recruitment threshold. Motor neurons in the stomatogastric system are identified by the muscles that they innervate (Maynard and Dando, 1974), so cell body impalement was not required for identification of the innervating motor neuron.

MG was identified as the unit that evoked EJPs in both the gm8 and gm9 muscles. The LP motor neuron was identified as the unit that evoked EJPs in muscles cpv6 and pl. The lateral gastric (LG) motor neuron was identified as the unit that ran in the medial ventricular nerve, not the $l v n$, and evoked EJPs in muscles gm $5 \mathrm{~b}$ and gm6a.

The preparation was superfused with saline having the following composition (in mM): $472 \mathrm{NaCl}, 10 \mathrm{KCl}, 16 \mathrm{CaCl}_{2}, 7 \mathrm{MgCl}_{2}, 10$ Tris $\mathrm{HCl}$, 10 maleic acid, 11 D-glucose ( $\mathrm{pH}$ adjusted to 7.4 with $\mathrm{NaOH}$ ). In a few experiments, oxygen was bubbled through the saline, but not for most of the experiments; no difference in EJP facilitation or depression was noticed between the two conditions. Without oxygenation, recordings were maintained for up to $5 \mathrm{hr}$ and muscle contractions were minimal, possibly due to the lack of oxygen. For low- $\mathrm{Ca}^{2+}$ saline, $\mathrm{Mg}^{2+}$ was substituted 1:1 for $\mathrm{Ca}^{2+}$. For high- $\mathrm{Mg}^{2+}$ saline, $\mathrm{Mg}^{2+}$ replaced $\mathrm{Na}^{+}$at a 1:2 ratio. Apamin and charybdotoxin, which were tested, were gifts from Dr. Irwin Levitan (Brandeis University, Waltham, MA).

For receptor blockade studies, $100 \mu \mathrm{l}$ of the glutamate antagonist Joro 
spider toxin JSTX-3 (Wako Pure Chemical Industries, Osaka, Japan), dissolved in saline, was pipetted directly into the bath at a concentration of $0.1 \mathrm{mg} / \mathrm{ml}$. The motor neuron-evoked EJPs immediately began to decrease in amplitude. When they reached $10 \%$ of their control amplitude, the JSTX was promptly washed from the bath. The EJPs remained at this low amplitude due to the essentially irreversible effects of JSTX (Kawai et al., 1991).

For desensitization studies, saline containing high concentrations of glutamate $(0.1-1 \mathrm{~mm})$ was perfused over the preparation. When the EJPs approached $10 \%$ of their control amplitude, the glutamate was washed off. Recordings were made during the addition and subsequent washout of glutamate.

In some experiments, muscle tension recordings were obtained by securing one of the attachment sites of the muscle to a force-displacement transducer (Grass, FT.03C) with a silk suture thread. No attempt was made to get an accurate measurement of muscle force.

Some data were collected directly onto chart paper and analyzed using a digitizing tablet (Summa graphics). Other data were digitized onto videotape, and analyzed off line.

Calculation of the facilitation index $\left(\mathrm{F}_{\mathrm{j}}\right)$. The facilitation index $\left(F_{i}\right)$ was calculated using measurements from a two-pulse paradigm (see Fig. 5). EJP amplitudes were corrected for changes in driving force using the following equations (Zucker, 1974):

$$
\begin{aligned}
& C_{1}=\frac{E_{1}}{1+E_{1} / V_{\text {rest }}}, \\
& C_{2}=\frac{E_{2}}{1+E_{2} /\left(V_{\text {rest }}+D\right)} .
\end{aligned}
$$

$C_{1}$ and $C_{2}$ are the corrected EJP amplitudes for the first and second EJPs, respectivcly. $E_{1}$ is the amplitude of the first EJP measured from the resting potential $\left(V_{\text {rest }}\right), E_{2}$ is the amplitude of the second EJP measured from $V_{\text {rest }}$ minus the contribution of the first $\operatorname{EJP}(D)$ at the time of the peak of the second EJP. The reversal potential was taken to be $0 \mathrm{mV}$ (Lingle, 1980). We defined the facilitation index $\left(F_{i}\right)$ for two consecutive EJPs as the ratio of the two corrected EJP amplitudes minus one:

$$
F_{i}=\left(C_{2} / C_{1}\right)-1 \text {. }
$$

This results in a number that is greater than zero if there is facilitation and less than zero if there is depression.

Calculation of depression. Depression was calculated as follows: the amplitudes of the last 10 EJPs of a stimulus train were averaged and expressed as a percentage of the initial EJP amplitude. In the majority of experiments the first gm 9 EJP was the largest. IIowever, in some experiments, particularly in small larval animals, there was considerable variation in EJP amplitude (see below). Since the largest EJP was generally within the first three of a train, we used the maximum of the first three EJPs as the value of the initial EJP.

Some gm 9 muscle fibers were capable of producing action potentials in response to MG-evoked EJPs. Muscle fibers that exhibited active responses were not used for calculation of depression.

Computer simulations. EJPs in $\mathrm{gm} 8$ and $\mathrm{gm} 9$ were modeled using the neural simulation program MARuo (Getting, 1989). The muscle was modeled as an isopotential sphere where the membrane voltage was calculated using the equation:

$$
\frac{d V}{d t}=-\frac{1}{C}\left(\frac{V-V_{\mathrm{rest}}}{R_{\text {input }}}+\left(V-E_{\mathrm{rev}}\right) G(t)\right)
$$

where $V$ is the membrane voltage; $C$ is the membrane capacitance, which was set to $30 \mathrm{nF}$, based on the charging curves for the muscles; $V_{\text {rest }}$ is the resting potential, which was set at $-60 \mathrm{mV} ; R_{\text {in }}$ is the input resistance of the muscle, which was set to $4.4 \mathrm{M} \Omega$ for $\mathrm{gm} 8$ and $1.2 \mathrm{M} \Omega$ for gm9 based on average experimental values (see Results); $E_{\mathrm{rev}}$ is the reversal potential for the synaptic current, which was taken to be $0 \mathrm{mV}$ (Lingle, 1980 ); and $G(t)$ is the time-dependent synaptic conductance, which was calculated in MARIO as a first-order process for channel opening and closing (Perkel et al, 1981; Getting, 1989). For the gm8 synapse, the opening time constant was $2.4 \mathrm{msec}$ and the closing time constant was $2.6 \mathrm{msec}$. For the gm9 synapse, the opening time constant was $0.6 \mathrm{msec}$ and the clusing time constant was $1.6 \mathrm{msec}$. These values were selected so as to match the shape of the actual EJP when the motor neuron was stimulated at $0.1 \mathrm{~Hz}$ (see below).

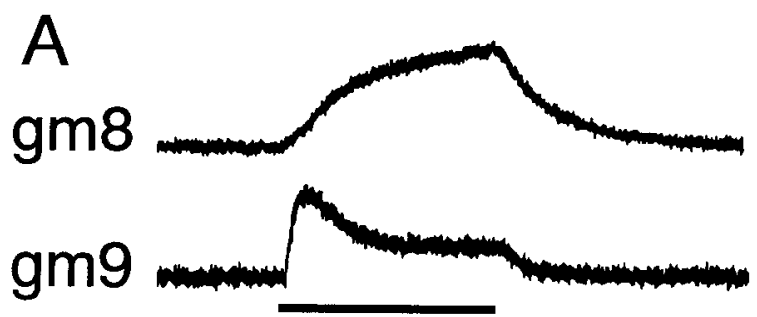

2 sec.
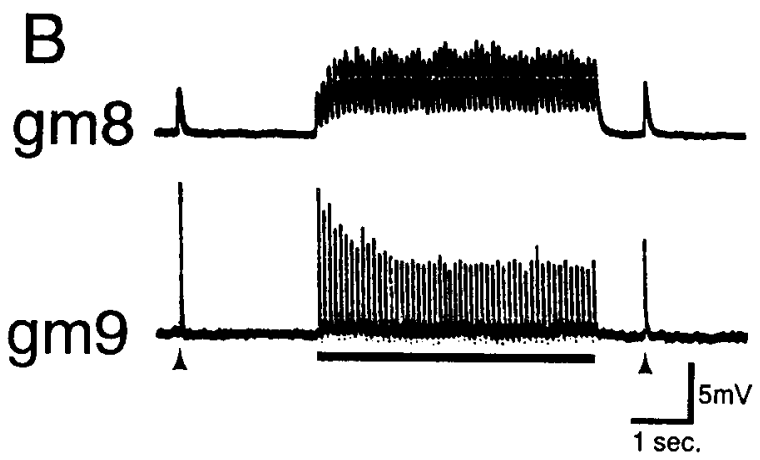

Figure 2. A, Tension recordings from the gm8 and gm9 muscles show that they respond differently to the same motor neuron input. When the MG motor neuron is extracellularly stimulated at $20 \mathrm{~Hz}$ (bar), both muscles contract. The gm 8 muscle shows a gradual increase in tension, while the gm9 muscle shows a rapid increase in tension followed by a relaxation. The rccordings, which were not made simultaneously, do not represent the relative forces of the two muscles, but rather show the differences in the timing of the maximum contractions. $B$, Simultaneous recordings of the EJPs evoked by the MG motor neuron in the gm8 and $\operatorname{gm} 9$ muscles show differences in amplitude over time with repeated stimulation. The EJP recorded in gm8 is initially much smaller and broader than that in $\mathrm{gm} 9$. A $10 \mathrm{~Hz}$ stimulus train (bar) results in an increase in the amplitude of the EJPs in gm8 and a decrease in the gm 9 EJPs. Immediately following the train, the EIP in gm8 is slightly larger than it was initially due to facilitation, while that in gm 9 is substantially smaller due to depression. Arrowheads indicate single EJPs to single stimuli.

Electron microscopy. The muscles were prepared for electron microscopy, following electrophysiology or in fresh preparations, according to standard procedures (Govind and Pearce, 1982). Briefly, this consisted of superfusing the muscles in situ in a primary fixative for $1 \mathrm{hr}$, after which they were dissected into individual muscles and fixed for a further $1 \mathrm{hr}$. The primary fixative was a mixture of glutaraldehyde and formaldehyde in a sodium cacodylate buffer. Following primary fixation, the muscles were brieffy rinsed in buffer solution and postfixed in osmium tetroxide for $1 \mathrm{hr}$ before being dehydrated in a graded ethanol series, cleared in propylene oxide, and embedded in plastic. Thin (75$100 \mathrm{~nm}$ ) sections of the tissue were cut and placed on Formvar-coated single-slot grids. They were double stained with uranyl acetate and lead citrate and examined with a Zeiss 9S or Siemens 102 electron microscope.

Innervation to matched $\operatorname{gm} 8$ and gm9 muscles was sampled in six lobsters, and from these one pair was serially sectioned for 7 and 5.7 $\mu \mathrm{m}$, respectively. Micrographs with a final magnification of $27,000 \times$ were used to make measurements of the area of neuromuscular synapses and the length of the presynaptic dense bars by procedures described previously (Govind and Pearce, 1982).

\section{Results}

\section{The innervation pattern of the $M G$ motor neuron}

The innervation of the foregut musculature of the adult lobster was previously described by Maynard and Dando (1974). We remapped the innervation pattern of the muscles in the region of gm 9 and gm 8 in juvenile animals to determine which muscles 


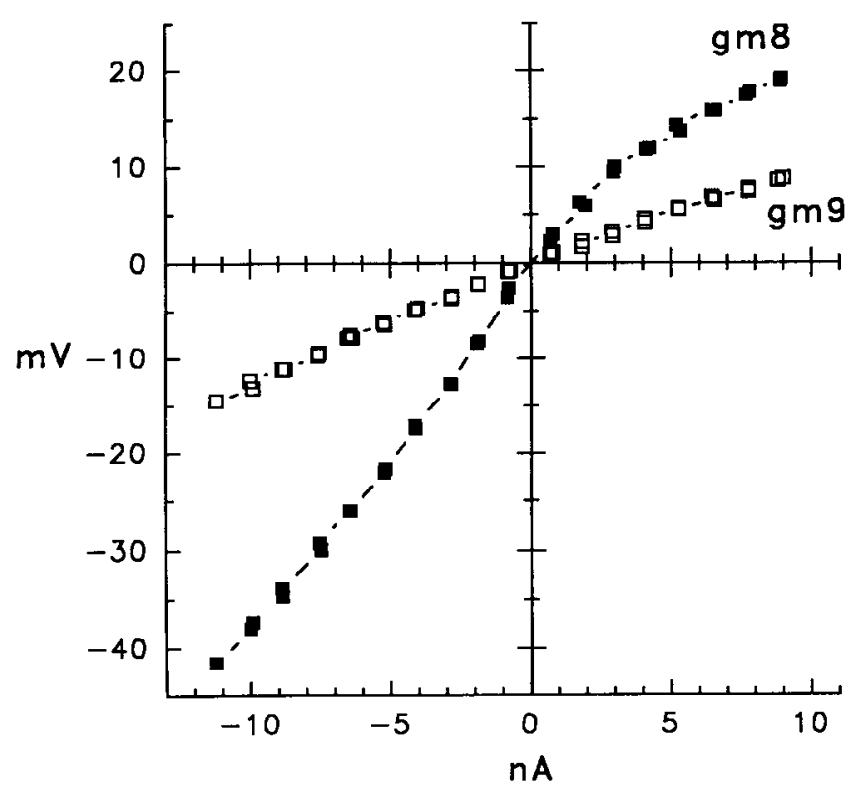

Figure 3. Current-voltage relations for gm 8 and gm 9 muscle fibers of the same animal show that gm8 fibers have a higher input resistance than those of gm9. Recordings for each muscle were made with two microclcctrodes near each other in the same muscle fiber. One electrode was used for passing current; the other, for recording membrane potential. The resting potential of $\mathrm{gm} 8$ was $-57 \mathrm{mV}$ and that of $\mathrm{gm} 9$ was $-62 \mathrm{mV}$.

were innervated by the MG motor neuron (Fig. 1). The majority of the gm 9 muscle fibers were exclusively innervated by the $\mathrm{MG}$ motor neuron. The MG motor neuron also innervated $\mathrm{gm} 8$, as well as the muscle fibers at the posterior margin of gm6a and at the anterior margin of the cpv6 muscle.

Portions of some muscles were dually innervated or had fibers that were electrically coupled to a ncighboring muscle that was innervated by a different motor neuron. While the gm 8 muscle was exclusively innervated by MG in at least four experiments, LG also sometimes produced observable EJPs $(<2 \mathrm{mV})$. Muscle fibers in the posterior portion of gm6a were also dually innervated by $M G$ and $L G$, although in at least two experiments, $L G$ did not innervate fibers in this region of the muscle. The muscle fibers at the posterior margin of gm9 and the anterior margin of cpv6, which abut each other, are dually innervated by the MG and the LP motor neurons (data not shown).

\section{Two different movements are evoked by the $M G$ motor neuron}

When the MG motor neuron was extracellularly stimulated at physiological frequencies $(10-20 \mathrm{~Hz})$, the gm 8 and gm 9 muscles responded with different time courses of contraction (Fig. 2A). The gm 8 muscle exhibited a slow onset of contraction and continued to contract throughout the motor ncuron stimulation. The gm9 muscle displayed an initial rapid contraction followed by a relaxation to a lower level of contraction. These movements were clearly visible by eye whenever the muscles were allowed to contract. Thus, the firing of a single motor neuron resulted in two different movements.

\section{Individual EJPs evoked in $g m 8$ and $g m 9$ differ in amplitude and duration}

The gm 9 muscle always contracted more rapidly than the gm 8 muscle. This is in part because the initial EJPs in gm9 during
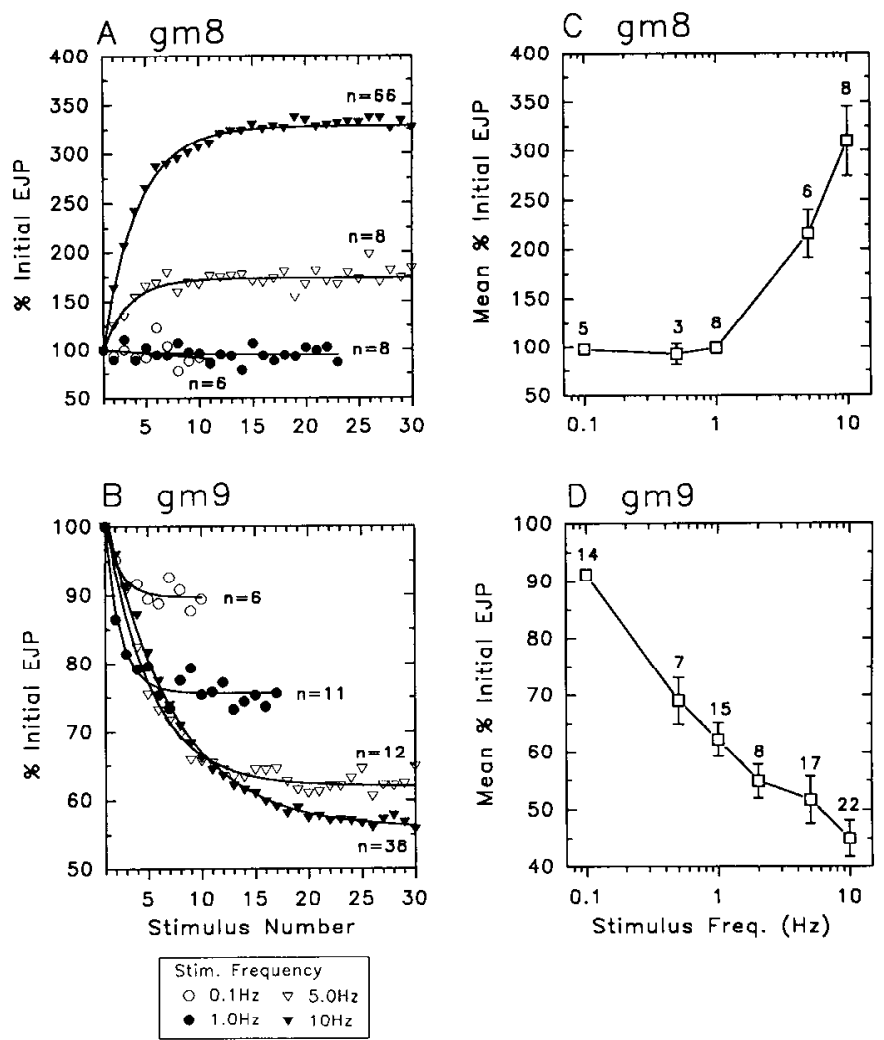

Figure 4. $A$ and $B$, The average time course of EJP facilitation and summation in $\mathrm{gm} 8(A)$ and depression in $\mathrm{gm} 9(B)$. The EJP amplitude, normalized to the amplitude of the first EJP but not corrected for summation (\% Initial EJP), is plotted versus stimulus number at four different stimulus frequencies: $0.1 \mathrm{~Hz}(0), 1 \mathrm{~Hz}(0), 5 \mathrm{~Hz}(\nabla)$, and $10 \mathrm{~Hz}$ $(\nabla) . A$, There is essentially no change in the gm8 EJP amplitude at 0.1 $\mathrm{Hz}$ and $1 \mathrm{~Hz}$, but significant increases are seen at 5 and $10 \mathrm{~Hz} . B$, The gm9 EJP amplitude progressively decreases starting at $0.1 \mathrm{~Hz}$. Note that the rate of decrease in gm9 EJP amplitude during a train is almost constant regardless of stimulus frequency, and that different steady state levels are attained at different times for the different stimulus frequencies. The curves are fitted with the following single exponential functions: $A, a=\left(1-e^{-t / r}\right) ; B, a * e^{-t / r}+c$; where $a$ is the maximum amplitude, $t$ is the stimulus number, $r$ is a time constant fitted to the curve, and $c$ is the constant amplitude attained after depression. In $A$ and $B$, the numbers by each plot represent the number of trials averaged at that stimulus frequency. Many fibers were sampled for each frequency and the plots represent grouped data from these fibers. $C$ and $D$, The dependence on frequency of EJP summation and facilitation in gm8 $(C)$ and depression in gm $9(D)$. Mean \% Initial EJP (population mean of the average of the last 10 EJPs in each 50 stimuli train divided by the mean initial amplitude for that experiment) is plotted versus stimulus frequency. In $C$ and $D$, the numbers above the error bars represent the number of preparations from which the responses were averaged.

a stimulus train were always larger than those in gm8 (Fig. $2 B$ ). At an interstimulus interval greater than $2 \mathrm{~min}$, the mean EJP amplitude rccorded in the gm9 muscle of similarly sized animals was $13.49 \pm 7.08 \mathrm{mV}(n=15)$, while that in $\mathrm{gm} 8 \mathrm{~b}$ was 2.44 $\pm 1.25 \mathrm{mV}(n=7)$.

Particularly large gm9 EJPs sometimes triggered small active responses in the muscle (not shown). These active potentials were up to $5 \mathrm{mV}$ in amplitude and acted to enhance the amplitude of the initial gm9 EJPs. Similar active responses could be elicited by injecting depolarizing current pulses into the muscle fiber (data not shown). Active responses were never observed in $\mathrm{gm} 8$ in response to current injection of motor neuron stimulation. 
A
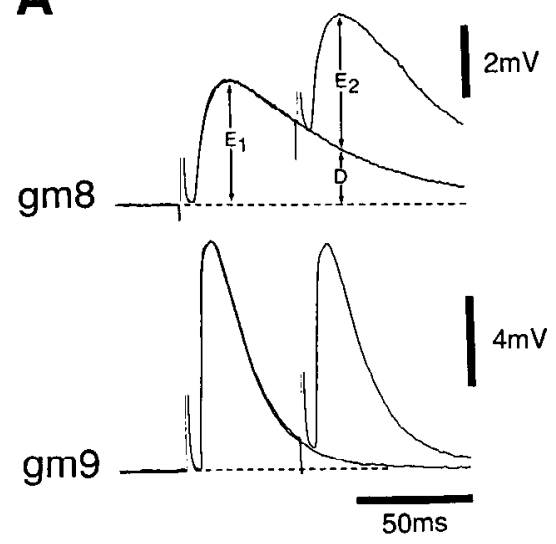

B

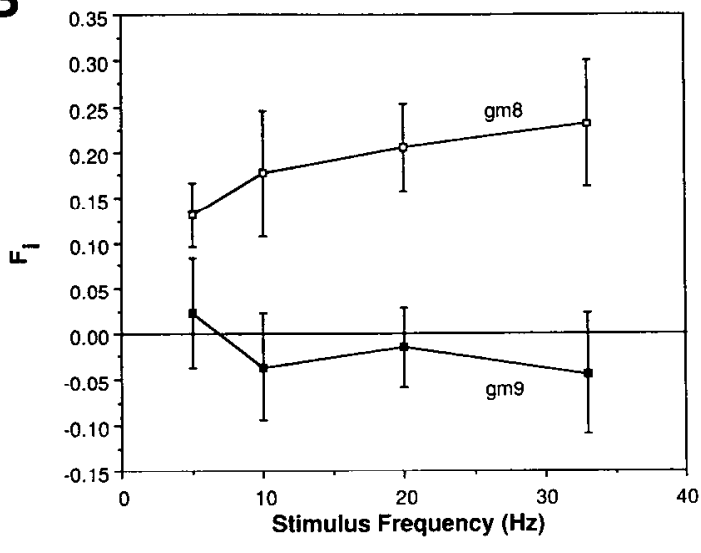

Figure 5. Two-pulse stimulus paradigm shows that $\mathrm{gm} 8$ exhibits facilitation and gm 9 does not. $A$, Twenty pairs of EJPs with an interpulse interval of $50 \mathrm{msec}$ were averaged. Twenty single EJPs were also averaged and overlaid over the paired EJPs. Note that the gm8 EJPs are broader and of lower amplitude than those in gm9. The amplitude of the single EJP at the time of the second peak $(D)$ was subtracted from the second peak to give the amplitude of the second EJP corrected for summation $\left(E_{2}\right)$ and compared to the peak amplitude of the first EJP $\left(E_{1}\right) . B$, The facilitation index $F_{i}$ (see Materials and Methods) is plotted versus instantaneous stimulus frequency (inverse interstimulus interval). Data were taken from $8 \mathrm{gm} 8$ muscle fibers and $13 \mathrm{gm} 9$ fibers.
In addition to differing in initial amplitude, the EJPs in the two muscles differed in time course. The EJPs in gm 8 always had slower rise times and longer decay times than those in gm9 (see Figs. 5, 8). This difference in EJP duration can partially account for the differences in the contractile responses of the muscles; the EJPs in gm8 were broad enough to overlap at interstimulus intervals of less than about $100 \mathrm{msec}$ whereas those in gm9 overlapped only at intervals less than $50 \mathrm{msec}$. As a result, the gm 8 EJPs summated at lower stimulus frequencies than those in gm 9 , causing gm 8 to depolarize gradually over time with continued stimulation.

The synaptic contacts made by the motor neuron onto these muscles are distributed along the length of the muscle fiber (see below). Therefore, the difference between the shapes of the EJPs is not due to differences in spatial attenuation caused by location of the recording site relative to the synapses. However, the difference in EJP durations may be due to postsynaptic differences in the input resistance of the fibers in the two muscles. In paired comparisons within the same animal, gm 8 muscle fibers always had a larger input resistance than those of gm9. Examples of the current-voltage relations for gm 8 and $\mathrm{gm} 9$ muscle fibers in the same animal are shown in Figure 3. These measurements were made with two electrodes in the same muscle fiber, one for injecting current, the other for recording voltage. The electrodes were placed as near to each other as possible to prevent voltage decrement along the length of the fiber. Input resistance was taken as the slope of the curve in the linear segment near the origin. The mean input resistance for $\mathrm{gm} 8$ fibers was 4.19 $\pm 1.22 \mathrm{M} \Omega(n=5$ fibers) while the mean input resistance for $\operatorname{gm} 9$ fibers was $1.20 \pm 0.15 \mathrm{M} \Omega(n=8$ fibers $)$. Since the input resistance of the gm 8 muscle fibers is significantly greater than that of the gm 9 fibers ( $P<0.05$, unpaired $t$ test), it is likely that the difference in the initial EJP amplitude is due to a difference in synaptic efficacy unrelated to postsynaptic input resistance.

\section{Differences in activity-dependent synaptic plasticity}

Aside from having different initial amplitudes and durations, the amplitudes of the EJPs evoked by MG in gm8 and gm9 changed differentially in response to repeated stimulation. When MG was stimulated at frequencies at or above $5 \mathrm{~Hz}$, the EJPs in gm8 exhibited summation and facilitation (see below), while the EJPs in gm9 showed depression (Figs. $2 B, 4$; see also below).

The EJP amplitudes recorded in gm 8 did not show any ap- preciable change in amplitude at stimulus frequencies of $1 \mathrm{~Hz}$ and below (Fig. 4A,C). At 5 and $10 \mathrm{~Hz}$, the apparent EJP amplitude (which includes summation) increased in an exponential fashion during a stimulus train, being well fit by a single exponential time constant (Fig. 4A).

The EJP amplitudes recorded in gm 9 exhibited a frequencydependent decrease in amplitude beginning at frequencies as low as $0.1 \mathrm{~Hz}$ (Fig. 4B,D). The time course of this EJP depression to a train of motor neuron spikes was well fit by a single exponential plus a constant, and the amplitudes at each of the different frequencies decreased at a similar rate when plotted against stimulus number (Fig. 4B).

Facilitation in gm 8 EJP amplitude was also measured using a two-pulse paradigm (Fig. $5 A$ ). The facilitation index $\left(F_{i}\right)$ is a measure of the change in EJP amplitude after removing confounding factors such as summation and changes in driving force (see Materials and Methods) (Zucker, 1974). Figure 5B shows that at instantaneous stimulus frequencies of $5 \mathrm{~Hz}$ or greater the EJPs in gm8 facilitated, with $F_{i}$ increasing to nearly 0.25 with stimulus frequencies above $20 \mathrm{~Hz}$. In contrast, using this paradigm, the EJPS in gm9 showed no facilitation and only a slight tendency toward depression in the two-pulse stimulus paradigm (Fig. 5).

\section{The EJPs in gm8 and gm9 exhibit different time courses of recovery from frequency-dependent effects}

The EJP amplitudes in gm 8 and gm 9 showed very different time courses of recovery (Fig. 6). The EJPs recorded in gm 8 at varying times after a $5 \mathrm{sec}, 10 \mathrm{~Hz}$ stimulus train, approached their initial amplitude within 4 sec (Fig. 6A). Following this, there appeared to be a slight depression in EJP amplitude when compared with the initial pulse (\% Recovery $>100 \%$ ). The EJPs recorded in gm9 were much slower to recover from the same stimulus paradigm; full recovery from a $5 \mathrm{sec}, 10 \mathrm{~Hz}$ stimulus train required more than $10 \mathrm{sec}$ (Fig. 6B).

\section{The changes in amplitude were not correlated with changes in muscle fiber input resistance}

It is possible that the changes in EJP amplitude were due to short-term voltage- or calcium-evoked changes in the postsynaptic membrane. For instance, a decrease in the input resistance of gm 9 muscle fibers might cause the EJP amplitudes to become smaller due to shunting of synaptic current. Conversely, an in- 

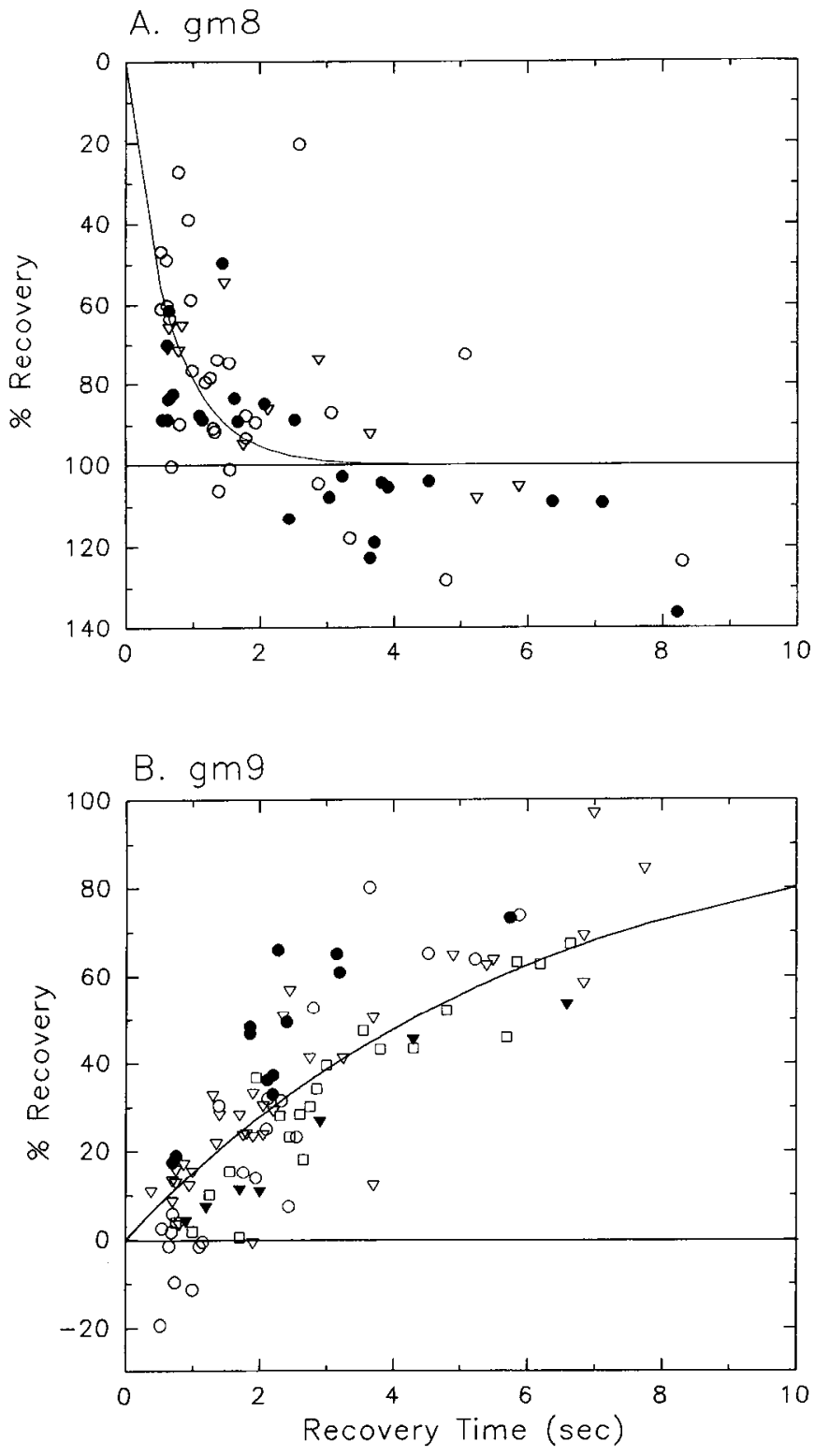

Figure 6. The EJPs in gm8 $(A)$ and $\mathrm{gm} 9(B)$ show different rates of recovery following a high-frequency stimulus train. The $M G$ motor neuron was stimulated for $5 \mathrm{sec}$ at $10 \mathrm{~Hz}$. A single test pulse was given at various times following the stimulus train; $100 \%$ recovery indicates that the EJP resulting from the test pulse reached the amplitude of the initial EJP. In the case of gm8, recovery values greater than $100 \%$ indicate that the test EJP was smaller than the initial EJP. For gm9, negative recovery values indicate that the test EJP was smaller than the final EJP of the stimulus train. The population data are fit with single exponential functions. The different symbols represent data from different preparations.

crease in the input resistance of the gm 8 muscle fibers could cause a larger voltage response to a constant-amplitude synaptic current.

A possible cause of postsynaptic shunting could be calciumactivated potassium channels in the muscle fiber membrane that might open during synaptic activity. Apamin and charybdotoxin block different types of calcium-activated potassium channels (Moczydlowski et al., 1988). We tested these two compounds to see if either type of calcium-activated potassium channel might be involved in shunting the synaptic current response and

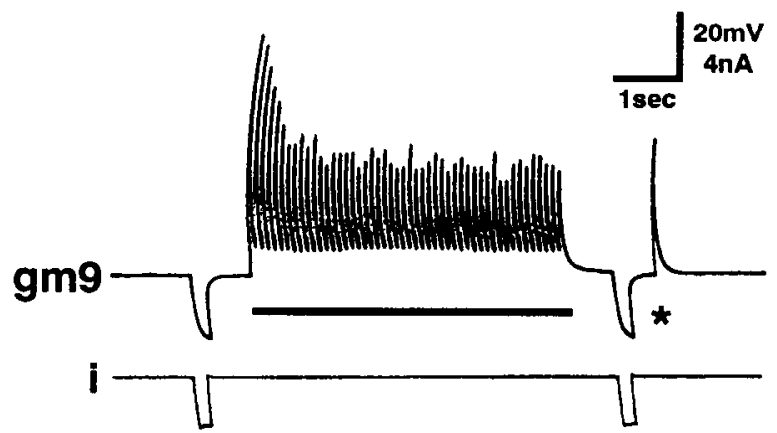

Figure 7. There is no change in input resistance in $\mathrm{gm} 9$ during depression. A gm 9 muscle fiber was impaled with two microelectrodes, one for current injection and the other for voltage recording. A constantcurrent pulse was injected into the muscle fiber immediately before and after $10 \mathrm{~Hz}$ stimulation of the motor neuron (bar). The motor neuron was stimulated once more after the second current pulse (star) to show that the EJP was still depressed. The traces were recorded on a curvilinear chart recorder.

found that up to $25 \mu \mathrm{M}$ apamin and $3 \mathrm{nM}$ charybdotoxin had no effect on the depression of gm9 EJPs (data not shown).

We directly tested the input resistance of the muscle fibers using small constant-current hyperpolarizing pulses $(n=3$ preparations) and found no change in input resistance in either muscle immediately following high-frequency stimulation of the motor neuron (gm9 response to stimulation is shown in Fig. 7). Notice that after the second hyperpolarizing current pulse, the amplitude of an EJP evoked by motor neuron stimulation was still only $57 \%$ of the amplitude of the initial EJP in the train. If this decrement in response were due to shunting of the synaptic current in muscle fiber, one would have expected to see a significant decrease in the input resistance of the muscle immediately following a train (see below), but none was seen (Fig. 7).

Further evidence that the activity-dependent changes in EJP amplitudes were not caused by changes in postsynaptic input resistance was provided by examining the shapes of the EJPs at different stimulus frequencies (Fig. 8). Changes in input resistance would alter the time course of the passive decay phase of the EJP due to alteration of the membrane time constant. To test this, the motor neuron was stimulated at various frequencies and the EJPs were averaged after they reached their steady state level (Fig. 8A,D). When the waveforms of the averaged EJPs were normalized to the same amplitude, there was an almost exact correspondence in their time courses (Fig. $8 B, E$ ), indicating that there was little or no change in membrane time constant after facilitation or depression.

We modeled the changes in EJP shape that one would expect to see if the change in amplitude were due to an alteration of muscle fiber input resistance. The solid line in Figure $8 \mathrm{C}$ represents a simulated $E J P$ in the gm 8 muscle whose shape and amplitude were modeled after the actual EJP when the motor neuron was stimulated at $0.1 \mathrm{~Hz}$. Increasing the input resistance ( $R_{\text {in }}$ ) of the muscle 10 -fold to $44 \mathrm{M} \Omega$ did not significantly enhance the amplitude of the model EJP, but did drastically alter its shape (Fig. $8 C$, dashed line). Further increases in input resistance did not greatly enhance the amplitude of the EJP. However, increasing the synaptic strength (Syn) from 0.68 to 1.12 resulted in an EJP that had a similar shape and amplitude to the EJP evoked by $5 \mathrm{~Hz}$ motor neuron stimulation (Fig. $8 \mathrm{C}$, 

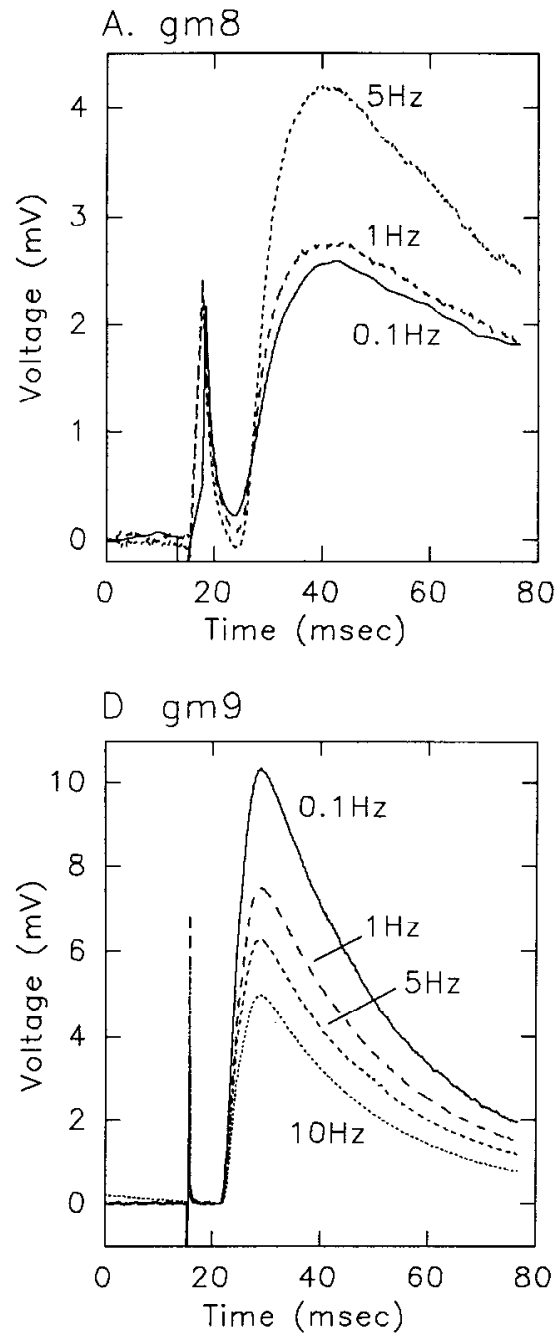

B. gm8-Normalized

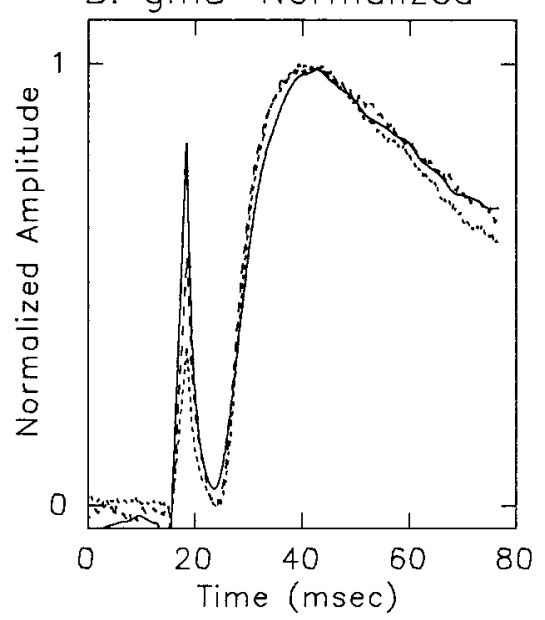

E. gm9-Normalized

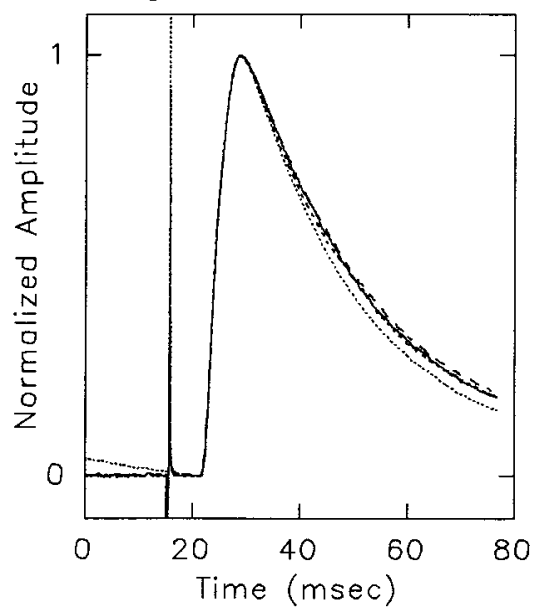

C. gm8-Model

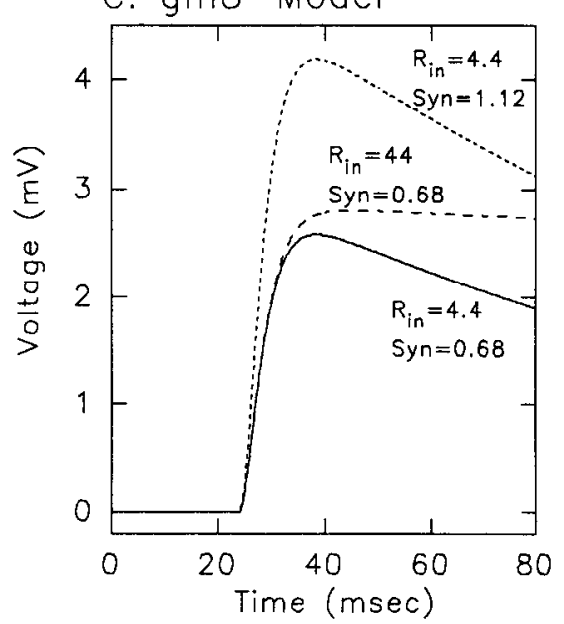

F. gm9-Model

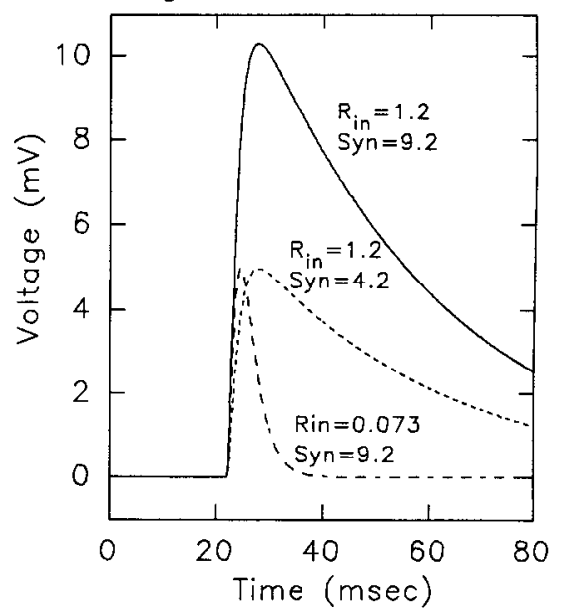

Figure 8. The EJPs do not change shape after facilitation in gm8 $(A, B)$ or depression in gm $9(D, E)$. $A$ and $D$, The MG motor neuron was stimulated at the frequencies indicated. After the EJP amplitudes reached steady state, 20 EJPs were averaged. As the stimulus frequency increases, the averaged EJPs in gm8 $(A)$ get larger, while those in $\mathrm{gm} 9(D)$ get smaller. $B$ and $E$, the averaged EJPs were normalized to the samc pcak amplitude. The normalized EJPs do not show significant variation in shape. $C$ and $F$, The EJPs in gm8 and gm9 were simulated using the program MARIO (see Materials and Methods). The solid lines are simulations of the EJP recorded when the motor neuron is stimulated at $0.1 \mathrm{~Hz}$. Changing the input resistance of the muscle fiber $\left(R_{\text {in }}\right)$ resulted in drastically different EJP shapes (dashed lines), whereas changing the synaptic strength (Syn) more closely approximated the size and amplitude of the EJP recorded at higher motor neuron stimulus frequencies (dotted lines).

dotted line). Increasing the synaptic strength parameter of the model is equivalent to increasing the number of receptors activated, as would occur during enhanced neurotransmitter release. These modeling results indicate that the frequency-dependent increase in gm8 EJP amplitude is probably not due to an increase in input resistance.

Similarly, we modeled the change in shape that would be expected if the decreasc in gm9 EJP amplitude were due to a decrease in muscle fiber input resistance. The solid trace in Figure $8 F$ is a simulated EJP, similar in shape and amplitude to the experimental EJPs recorded when the motor neuron was stimulated at $0.1 \mathrm{~Hz}$. The input resistance of the muscle fiber was lowered to the point at which the amplitude of the model EJP equaled that of the experimental EJP evoked by $10 \mathrm{~Hz}$ motor neuron stimulation. The resulting input resistance was less than $1 / 16$ th of the original input resistance, and the EJP had a faster rise time as well as a faster passive decay phase. Decreasing the synaptic strength from 9.2 to 4.2 while leaving the input resistance constant resulted in an EJP that more closely approximated the shape of the EJP evoked by $10 \mathrm{~Hz}$ motor neuron stimulation. These results indicate that the frequencydependent decrease in gm9 EJP amplitude is not caused by a decrease in the muscle fiber input resistance, but could be caused by a decrease in the number of receptors activated. Either decreasing the neurotransmitter released from the motor neuron or desensitization of the postsynaptic receptors would be consistent with this result.

Shunting of the FJP did have a very slight effect at high stimulus frequencies. For instance, at $10 \mathrm{~Hz}$, the passive decay phase of the gm $9 \mathrm{EJP}$ is slightly faster than at the slower stimulus frequencies (Fig. $8 E$, dotted line). At this frequency, there is some overlap between consecutive EJPs resulting in a decreased input resistance. This result was predicted by the model and found to be true for gm8 as well (data not shown). However, this effect is not enough to account for the decrease in amplitude that is observed. 


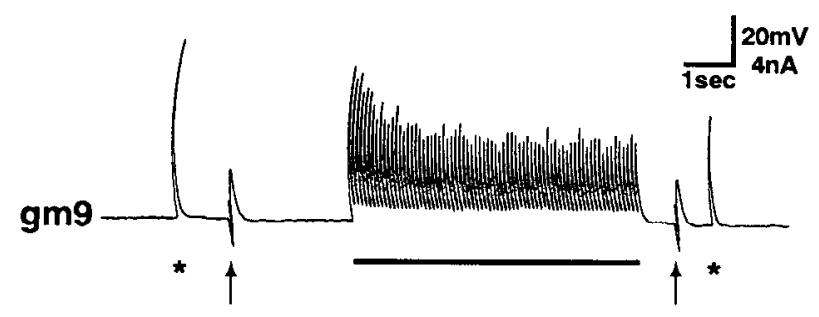

Figure 9. The response of gm9 to iontophoresed glutamate does not change significantly during depression. Glutamate ( $1 \mathrm{~mm}$ ) was iontophoresed $(-100 \mathrm{nA}, 50 \mathrm{msec}$, arrows) prior to and immediately after $10 \mathrm{~Hz}$ stimulation of the motor neuron (bar). The motor neuron was stimulated to evoke a single EJP before the first iontophoretic pulse and after the second (stars), showing that the EJP amplitude was still depressed after the second iontophoretic pulse.

\section{The depression of gm9 EJPS is not due to receptor desensitization}

Glutamate is the presumed neurotransmitter at this and most excitatory lobster neuromuscular junctions (Atwood, 1976; Lingle, 1980; Govind and Lingle, 1987). The muscles are sensitive to iontophoretic pulses of glutamate only at "hot spots." These hot spots are thought to be located at or near neuromuscular junctions where the receptors are likely to be clustered (Lingle, 1980).

We found that large iontophoretic pulses of glutamate onto either gm8 or gm9 evoked depolarizing responses that desensitized with repeated application. This indicates that the receptors on both muscles are capable of desensitization.

We used small iontophoretic pulses of glutamate to test whether the depression of gm9 EJPs is caused by receptor desensitization (Fig. 9). The amplitude of the glutamate pulse was adjusted so that it would not produce desensitization of a subsequent pulse $10 \mathrm{sec}$ after the initial pulse. Test pulses of glutamate were applied before and after a train of EJPs evoked by motor neuron stimulation (Fig. 9). There was no significant change in the response to iontophoretically applied glutamate following the EJP train even though a subsequent single motor neuron-evoked EJP (right star, Fig. 9) was still reduced to $62 \%$ of the initial EJP amplitude. Thus, it is unlikely that receptor desensitization accounts for the activity-dependent depression of EJP amplitude in gm9. However, we cannot exclude the possibility that the exogenously applied glutamate failed to reach the synaptic receptors, but instead excited nonsynaptic receptors clustered near the terminals.
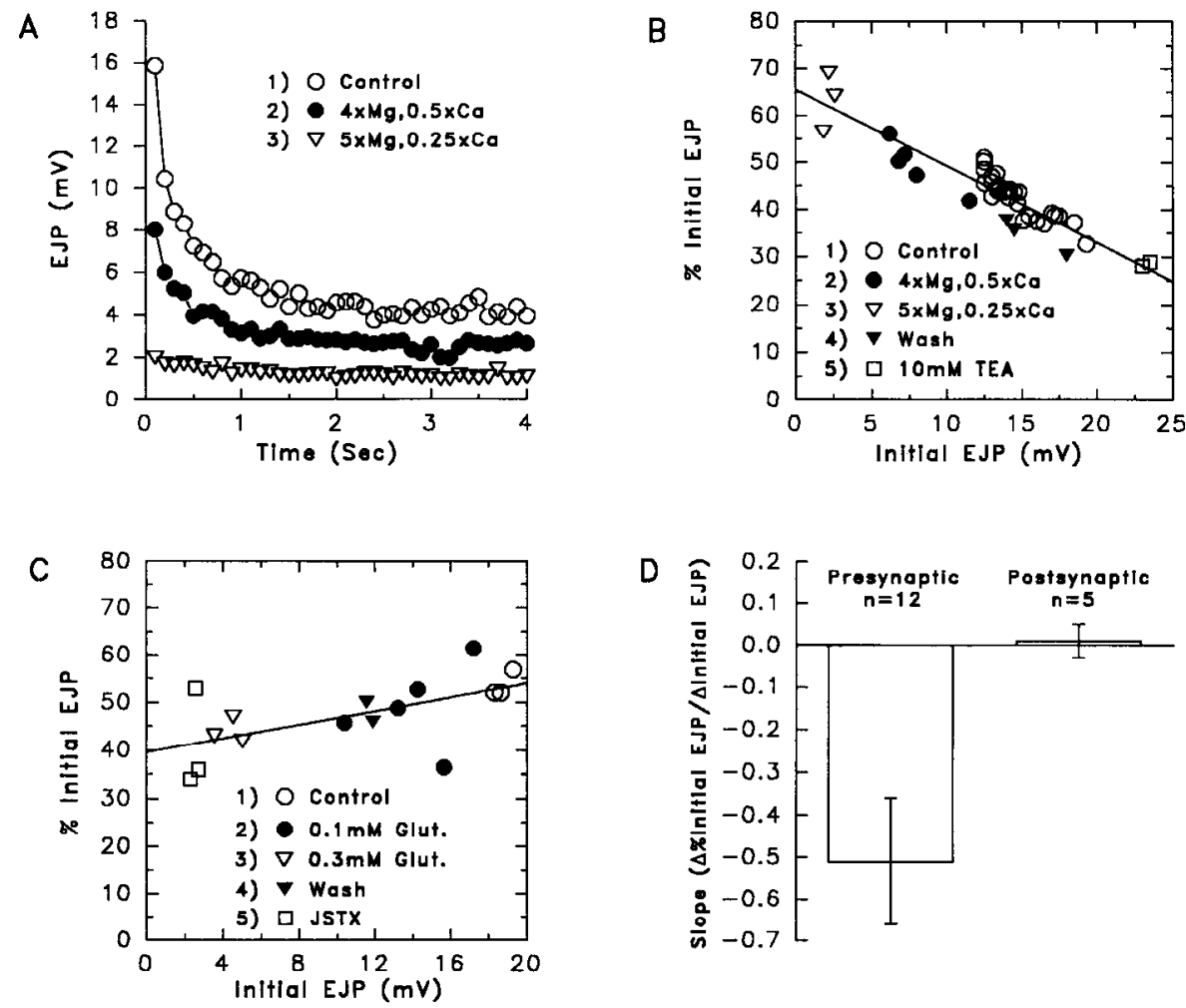

Figure 10. Manipulations that lower EJP amplitude by decreasing release also decrease depression in gm9, while those that lower EJP amplitude by affecting the postsynaptic response do not. $A, \operatorname{gm} 9$ EJP amplitudes in response to repetitive stimulation of MG under different conditions. Manipulations that change release of neurotransmitter were performed on this gm 9 muscle fiber. Neurotransmitter release was lowered by decreasing $\mathrm{Ca}^{2+}$ and increasing $\mathrm{Mg}^{2+}(\boldsymbol{e}, \nabla)$. The EJP amplitude is plotted versus time for a $10 \mathrm{~Hz}$ stimulus under each condition. $B$, The average amplitude of the last $10 \mathrm{gm} 9 \mathrm{EJPs}$ in each $4 \mathrm{sec}, 10 \mathrm{~Hz}$ train is expressed as a percentage of the initial EJP amplitude and plotted versus the initial EJP amplitude (i.e., the first EJP in the train). The three conditions shown in $A$ are plotted. The preparation was then washed ( $\nabla)$ and release was increased with TEA $(\square)$ presumably by broadening the presynaptic spike. The results from all of these manipulations were fit by linear regression with a line that has a negative slope. $C$, Manipulations that change the amplitude of the postsynaptic response through receptor desensitization ( $\bullet$, $\nabla$ ) or receptor blockade by JSTX ( $\square$ ) were performed on this gm9 fiber. These points were fit with a line that has a positive slope. $D$, Manipulations that change EJP amplitude by changing neurotransmitter release (Presynaptic) cause a change in depression that correlates with EJP amplitude. Manipulations that change the EJP amplitude without affecting release (Postsynaptic) do not cause a change in the amount of depression. The average slopes from the linear regressions for the plots of depressed EJP amplitude for all experiments, such as those in $B$ and $C$, are shown. 
The depression of $g m 9$ EJPs is probably due to a presynaptic mechanism

If synaptic depression at gm9 were due to a presynaptic mechanism, such as transmitter depletion, then one would predict that manipulations that alter presynaptic release would change the amount of depression in a different manner than manipulations that affect only the postsynaptic membrane. In contrast, if depression were due to a postsynaptic mechanism, then one would expect that any manipulation that affects EJP amplitude, regardless of whether the manipulation acts presynaptically or postsynaptically, would change the amount of depression in a similar fashion (Schlapfer et al., 1974).

To distinguish between a presynaptic and a postsynaptic mechanism of EJP depression in gm9, we lowered the EJP amplitude in gm 9 by decreasing transmitter release. External calcium concentration $\left(\left[\mathrm{Ca}^{2+}\right]_{\omega}\right)$ was decreased, while external magnesium concentration $\left(\left[\mathrm{Mg}^{2+}\right]_{o}\right)$ was increased, thereby reducing the $\mathrm{Ca}^{2+}$ influx into the presynaptic terminals and reducing neurotransmitter release. When the EJP amplitude was reduced in this manner, the amount of depression decreased in proportion to EJP amplitude (Fig. $10 A, B$ ). When $10 \mathrm{mM}$ tetraethylammonium (TEA) was added to normal saline, causing action potential broadening, EJPs became larger, presumably due to the augmentation of transmitter released per spike. Increasing the EJP amplitude in this fashion enhanced the amount of depression (Fig. 10B). These presynaptic manipulations resulted in an inverse linear relationship between the initial EJP amplitude of a $10 \mathrm{~Hz}$ stimulus train and the depressed amplitude of the final EJPs of the train (expressed as a percentage of the initial EJP amplitude) (Fig. 10B). This suggests that when more transmitter was released with each action potential, there was more synaptic depression.

In another set of experiments, we lowered the EJP amplitude by decreasing the number of postsynaptic receptors available. We did this in two ways (Fig. 10C). The first was to desensitize many of the receptors with bath-applied glutamate. The second was to block a large percentage of the receptors with the glutamate antagonist JSTX (Kawai et al., 1991). Both of these manipulations produced the same result, namely, that there appeared to be a slight increase in the amount of depression as the EJP amplitude decreased.

The results from all the experiments where manipulations were used to change EJP amplitude are summarized in Figure $10 D$. The slopes of the linear regressions, such as those in Figure $10, B$ and $C$, obtained from all the experiments where EJP amplitude was altered through presynaptic or postsynaptic mechanisms were averaged. These slopes are a measure of the dependence of depression on EJP amplitude; a zero slope indicates no dependence. Altering the presynaptic release of neurotransmitter by altering $\left[\mathrm{Ca}^{2+}\right]_{o}$, or adding $1 \mu \mathrm{M} \mathrm{Cd^{2+ }}$ or TEA resulted in an average slope ( $\Delta \%$ Initial EJP/ $\Delta$ Initial EJP) of $-0.51 \pm 0.15(n=12)$. Lowering the amplitude of the EJP through postsynaptic desensitization by exogenous glutamate or application of JSTX resulted in an average slope of $0.01 \pm 0.04$ $(n=5)$. These two average regressions differ significantly as determined by an ANOVA. Thus, manipulations that affected transmitter release had a large effect on the amount of depression, whereas those that affected the postsynaptic receptors had little, if any, effect on the amount of depression. These results suggest that depression at the MG synapses on $\mathrm{gm} 9$ is due to a presynaptic mechanism.
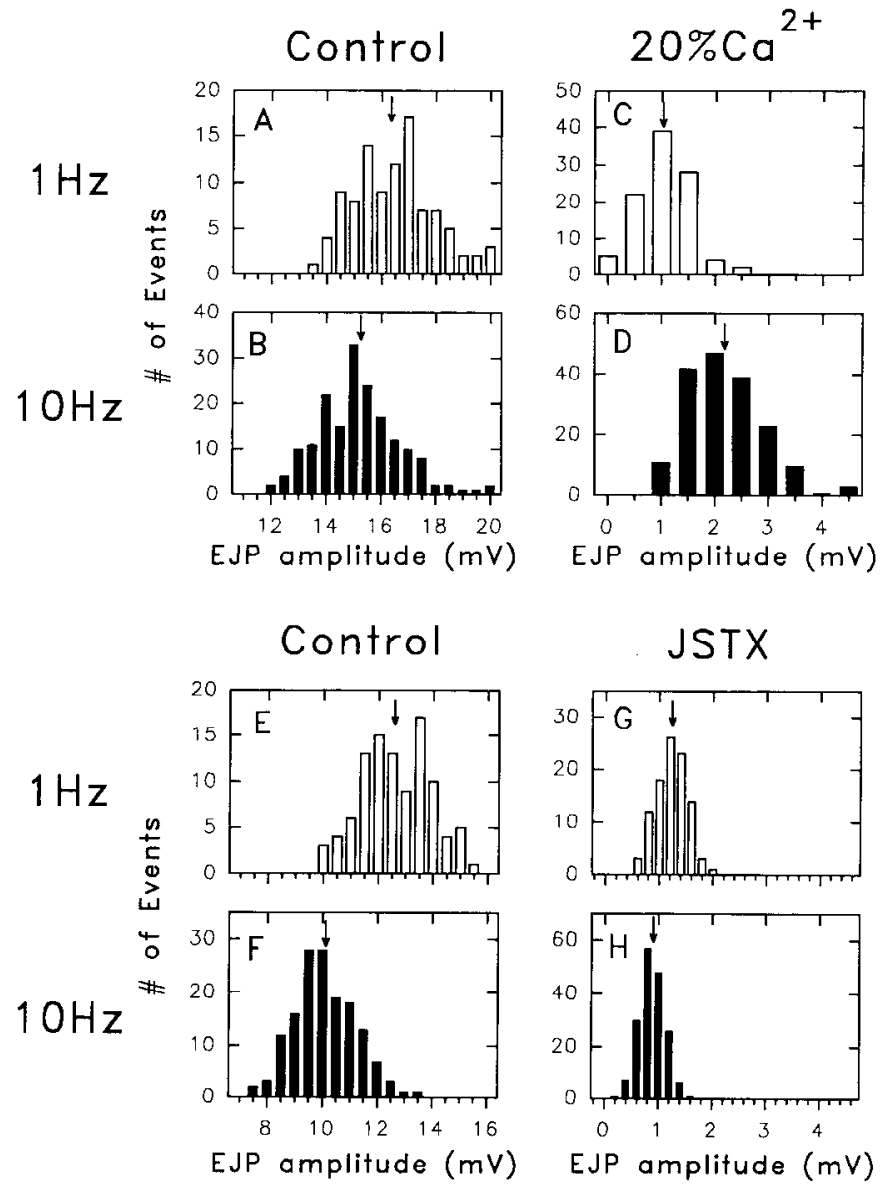

Figure 11. gm9 synapses exhibit facilitation under conditions that drastically reduce transmitter release. However, large reductions in EJP amplitude caused by postsynaptic receptor blockade do not prevent depression. The histograms were generated from data obtained after the responses had reached steady state at the indicated stimulation frequency. These results were obtained from a fifth stage postlarval animal, which shows a greater variability in EJP amplitude than older, larger animals (see Results). $A-D$, Histograms of gm9 EJP amplitudes in response to $1 \mathrm{~Hz}$ and $10 \mathrm{~Hz}$ motor neuron stimulation in control and low-calcium, high-magnesium saline ( $20 \%$ calcium saline). In control saline, stimulation at $10 \mathrm{~Hz}(B)$ results in a shift of the population and its mean (arrow) toward lower-amplitude EJPs with respect to stimulation at $1 \mathrm{~Hz}(A)$, indicating that there is more depression at $10 \mathrm{~Hz}$ than at $1 \mathrm{~Hz}$. In $20 \%$ calcium saline, the release of neurotransmitter is reduced, resulting in an average EJP amplitude at $1 \mathrm{~Hz}(C)$ that is less than $10 \%$ of the control value. At this level of release, some synaptic failures are observed at $1 \mathrm{~Hz}(\mathrm{EJP}$ amplitude $=0 \mathrm{mV})$. When the motor neuron is stimulated at $10 \mathrm{~Hz}(D)$, the population and its mean (arrow) shift toward larger EJPs and no failures are observed, indicating facilitation, not depression. $E-H$, Histograms of gm 9 EJP amplitudes obtained from a different animal in response to $1 \mathrm{~Hz}$ and $10 \mathrm{~Hz}$ motor neuron stimulation in control saline and after treatment with JSTX. In control saline, stimulation at $10 \mathrm{~Hz}(F)$ results in a shift of the EJPs toward lower amplitudes with respect to stimulation at $1 \mathrm{~Hz}(E)$. After treatment with JSTX, the average EJP at $1 \mathrm{~Hz}$ stimulation $(G)$ is reduced in amplitude to $10 \%$ of its control value, but no synaptic failures are ever observed. At $10 \mathrm{~Hz}$ stimulation $(H)$, there is still a shift in the population of EJP amplitudes and its mean (arrow) to lower values.

\section{When transmitter release is lowered sufficiently, gm9 synapses exhibit facilitation}

At synapses with a large number of release sites the amount of neurotransmitter released with each impulse does not vary, but with a smaller number of release sites, the amount can vary due to the probabilistic nature of release (Katz and Miledi, 1967). 


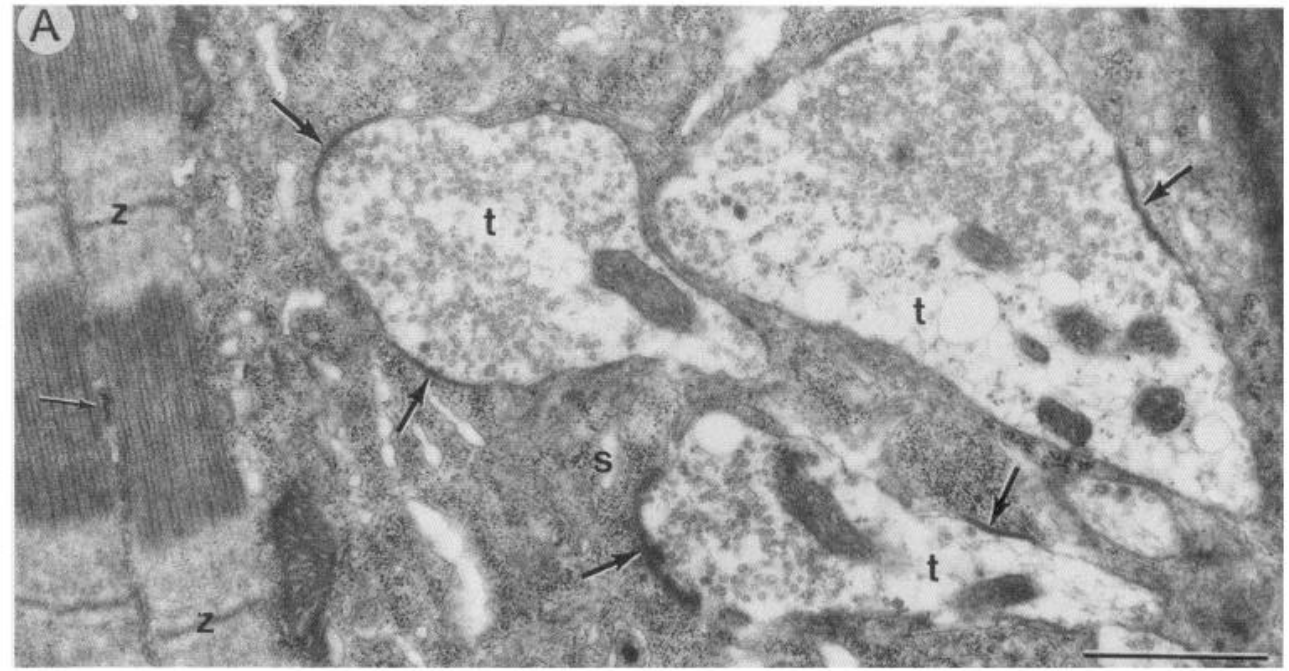

Figure 12. A, Fine structure of excitatory neuromuscular terminals $(t)$ filled with clear, spherical synaptic vesicles and making synaptic contact (large arrows) with muscle granular sarcoplasm $(s)$ on a $\mathrm{gm} 9$ muscle fiber. A well-defined sarcomere between adjacent $z$-lines $(z)$ is seen with an A-band between two half I-bands and a diad (small arrow) in the middle of the A-band. Magnification, $26,000 \times . B$ and $C$, Cross-sectional and sagittal views, respectively, of a presynaptic dense bar (arrows) showing clear vesicles clustered around the bar and aligned on either side of the bar. Magnification, $60,000 \times$. Scale bars, $A, 1 \mu \mathrm{m} ; B$ and $C, 0.5 \mu \mathrm{m}$.
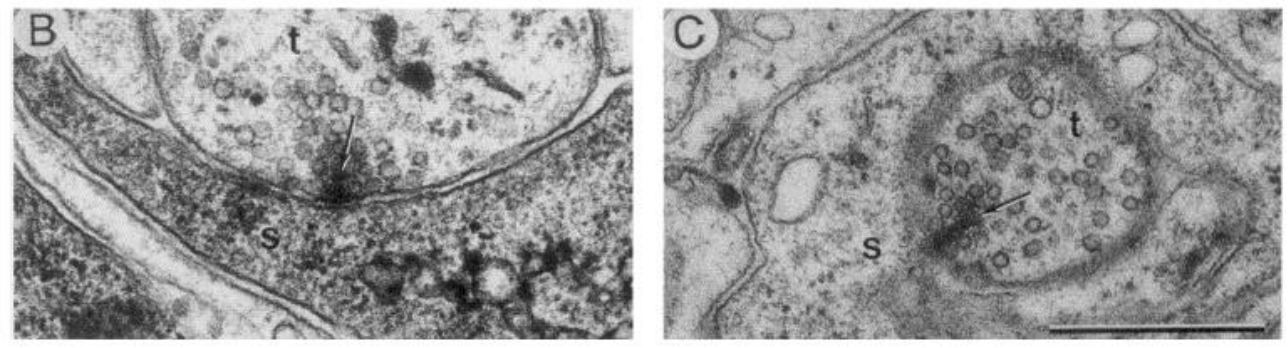

In early juvenile animals (stages 4-6), there was a large variability in EJP amplitude (Fig. 11A) presumably due to the small size of the muscle fibers and the small number of synaptic release sites.

We took advantage of the variability in EJP amplitude in juvenile animals to investigate what would happen to EJP amplitude distribution when the probability of release was lowered by decreasing $\left[\mathrm{Ca}^{2+}\right]_{o}$. In normal saline, when the motor neuron was stimulated at $1 \mathrm{~Hz}$, there was some depression of the EJP amplitude in gm9. When the stimulus frequency was increased to $10 \mathrm{~Hz}$, there was further depression. Histograms of EJP amplitude (Fig. 11 $A, B$ ) show that, as expected for the depression of gm 9 synapses, the distribution of EJP amplitudes shifts to the left at the higher stimulus frequency. We then lowered $\left[\mathrm{Ca}^{2+}\right]$ in the bath to $20 \%$ of the normal concentration and repeated the motor neuron stimulation at $1 \mathrm{~Hz}$ and $10 \mathrm{~Hz}$ (Fig. $11 C, D$ ). At $1 \mathrm{~Hz}$ stimulation (Fig. $11 C$ ), the average EJP amplitude was less than $1 / 10$ th of its control value. Under these conditions, $5 \%$ of the motor neuron stimuli in the train failed to evoke an EJP. These failures are shown as zero amplitude EJPs (Fig. 11C). When the motor neuron was then stimulated at $10 \mathrm{~Hz}$, instead of exhibiting depression, the EJPs showed facilitation (Fig. 11D); the average EJP more than doubled in amplitude and no synaptic failures were observed.

A similar switch from synaptic depression to facilitation was observed in each of seven early juvenile animals where release was substantially lowered by reducing $\left[\mathrm{Ca}^{2+}\right]_{o}$. Under identical conditions, in simultaneous paired comparisons, the gm8 synapse continued to exhibit synaptic facilitation (not shown).

Reduction of the EJP amplitude through postsynaptic receptor blockade or desensitization did not cause the gm 9 synapses to change from depression to facilitation. In two experiments with early juvenile lobsters, JSTX was used to decrease EJP amplitude to levels similar to those obtained with low $\left[\mathrm{Ca}^{2+}\right]_{o}$, and in one experiment glutamate desensitization was utilized. Results from one of the JSTX experiments are shown in Figure $11 E-H$. In control saline, motor neuron stimulation at $10 \mathrm{~Hz}$ caused a decrease in the mean EJP amplitude and a shift to the left of the entire population with respect to stimulation at $1 \mathrm{~Hz}$ (Fig. $11 E, F$ ). The mean value at $10 \mathrm{~Hz}$ was $81 \%$ of that at 1 $\mathrm{Hz}$. After a brief treatment with JSTX, the mean EJP amplitude at $1 \mathrm{~Hz}$ was reduced to about $1 / 10$ th of its control value (Fig. $11 G$ ). Unlike the results with low $\left[\mathrm{Ca}^{2+}\right]_{o}$, treatment with JSTX did not cause an increase in the incidence of synaptic failures, even though the EJPs were reduced to the same extent. Stimulation at $10 \mathrm{~Hz}$ resulted in a decrease in the mean EJP amplitude and a shift in the population of EJP amplitudes to the left (Fig. $11 H$ ). The mean value at $10 \mathrm{~Hz}$ in JSTX was $72 \%$ of that at $1 \mathrm{~Hz}$ (Fig. $11 G, H$, arrows), indicating that there was slightly more depression than in normal saline. Thus, reduction of EJP amplitude through postsynaptic receptor blockade did not remove depression.

\section{Ultrastructural differences between the muscles}

We examined the terminals of the MG motor neuron in an adult animal using electron microscopy to determine if there were morphological differences that may account for the differences in synaptic plasticity. The fine structure of both the neuromuscular synapses and the muscle fibers differed between the two muscles. The gm 8 muscle had sarcomeres of $8 \mu \mathrm{m}$ average length, dyadic contacts (where sarcoplasmic reticulum meets T-tubule) toward the ends of the sarcomeres, and a thin-to-thick myofilament ratio of $6: 1$. In contrast, the gm 9 muscle had sarcomeres that averaged $4 \mu \mathrm{m}$ in length, dyads in the middle of the A-band, 
and a low thin-to-thick filament ratio of 3:1. These data suggest that $\mathrm{gm} 8$ is similar to a typical crustacean slow muscle while gm9 is more similar to a fast muscle.

Branches of the MG axon ramify over the gm8 and gm9 muscles, providing multiterminal innervation to the muscle fibers (Fig. 12). The innervation that was usually located along the periphery of the muscle fiber (although some fine branches were found within the fiber) typically consisted of en passant synaptic terminals. These terminals were recognizable as aggregations of clear, round synaptic vesicles and synaptic contacts with the muscle membrane adjacent to granular sarcoplasm (Fig. $12 A)$. At these contacts, the presynaptic and postsynaptic membranes were densely stained and separated by a uniform cleft. Also characteristic of these synaptic contacts was an active site for transmitter release denoted by a presynaptic dense bar with clear vesicles aligned along its border (Fig. 12B). This arrangement of the vesicles along the bar was particularly well seen in fortuitous thin sections that grazed the length of the bar (Fig. $12 C)$. Mitochondria were present in these terminals and often a few dense-core vesicles. This fine structure of synaptic terminals was qualitatively similar between the gm 8 and gm 9 muscle fibers.

A quantitative analysis of synaptic contacts and presynaptic dense bars was undertaken from serially thin-sectioned tissue and revealed that the synapses were significantly larger (Student's $t$ test) in gm 9 than in gm 8 (Fig. 13A). The presynaptic dense bars within these synapses were similar in mean length between the two muscles (Fig. 13B) although their distribution was markedly different. Thus, while all of the gm 9 synapses possessed a dense bar almost one-fifth of the gm 8 synapses were without one. The gm8 synapses with dense bars had either one or two, while many of the gm 9 synapses had three to five dense bars (Fig. 13C). On average the larger gm9 synapses tended to support many more bars than the smaller gm 8 synapses.

\section{Discussion}

We have shown that the EJPs evoked by the MG motor neuron facilitate in one muscle (gm8) and depress in another (gm9). Our results suggest that there is presynaptic basis for this difference; thus, a single motor neuron can exhibit drastically different release properties at different axon terminals. In the case of gm8 and gm 9 innervation, postsynaptic differences also contribute to and amplify the differences in synaptic efficacy. Since the rate of tension development and its magnitude depend upon the amplitude and duration of membrane depolarization in crustacean muscles (Atwood and Dorai Raj, 1964), the initial EJP amplitudes and the changes in EJP amplitudes over time play a large role in determining the temporal sequence of muscular contraction. These peripheral differences result in two different movements produced by a single motor neuron.

\section{Presynaptic differences in the neuromuscular junctions}

Short-term, homosynaptic facilitation is a well-established phenomenon that is believed to be due to the buildup of residual calcium in the presynaptic terminal that leads to enhanced transmitter release (Katz and Miledi, 1968; Zucker, 1974, 1989; Sarrazin, 1987; Dudel, 1989; Delaney et al., 1991; Hochner et al., 1991; Swandulla et al., 1991; Zucker et al., 1991). Our evidence supports the notion that facilitation at the gm8 terminals is presynaptic in origin, and thus similar to other well-studied examples in lobster and crayfish neuromuscular junctions.

Our results are also consistent with a presynaptic locus for
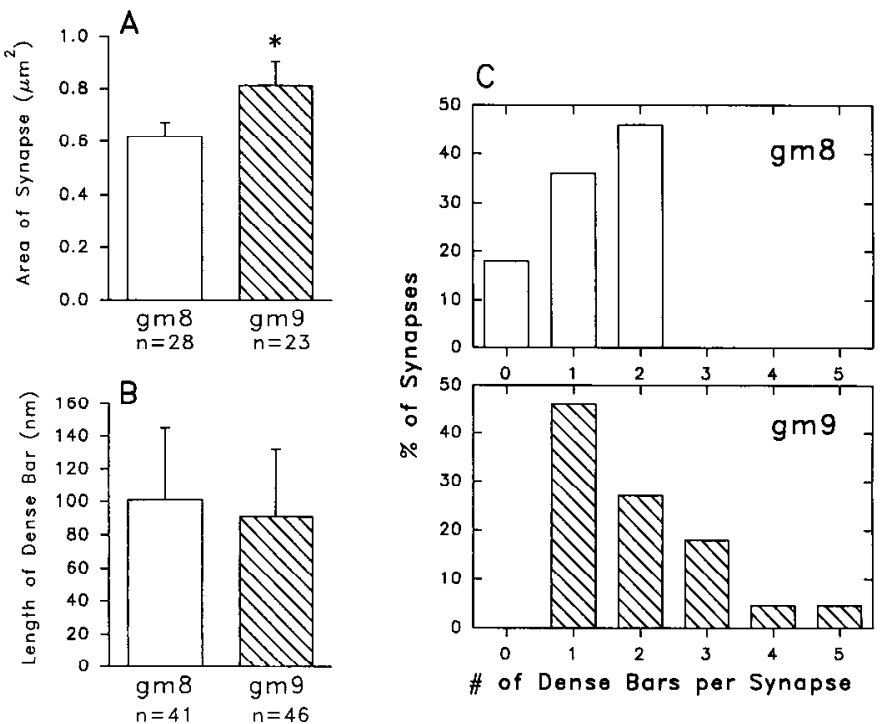

Figure 13. Fine structural differences between the presynaptic terminals of $\mathrm{MG}$ on gm8 and gm9. One gm8 muscle and one gm9 muscle were serially sectioned for 7 and $5.7 \mu \mathrm{m}$, respectively. $A$, The mean area of the synapses on gm9 $\left(0.813 \pm 0.089 \mu \mathrm{m}^{2}\right)$ was significantly greater $\left({ }^{*}, P<0.05\right)$ than that of the $\mathrm{gm} 8$ synapses $\left(0.618 \pm 0.053 \mu \mathrm{m}^{2}\right) . B$, The mean length of the presynaptic dense bars did not differ significantly between $\mathrm{gm} 8(101 \pm 44 \mathrm{~nm})$ and $\mathrm{gm} 9(91 \pm 41 \mathrm{~nm}) . C$, gm8 synapses (top) have fewer presynaptic dense bars than do gm 9 synapses (bottom). Note that $18 \%$ of the synapses in gm8 have no dense bars whereas all of the gm 9 synapses have at least one dense bar. Furthermore, $27 \%$ of gm 9 synapses have three or more dense bars, whereas none of the gm 8 synapses had more than two dense bars.

the depression of gm9 EJPs. First, there is no detectible change in input resistance or EJP waveform during depression. Computer simulations indicate that a large change in input resistance would be required to cause the decrease in amplitude that is observed during depression. Such a decrease in input resistance would have also resulted in a dramatic alteration of the EJP waveform. Second, there is no detectible change in receptor sensitivity during depression. Lastly, manipulations that change the EJP amplitude by altering release change the extent of depression whereas manipulations that alter postsynaptic responsiveness do not affect depression.

Large reductions in extracellular $\left[\mathrm{Ca}^{2+}\right]$ result in a loss of depression and the appearance of facilitation at $\mathrm{gm} 9$ synapses. It seems that the gm 9 terminals are capable of both depression and facilitation, but in normal $\left[\mathrm{Ca}^{2+}\right]_{o}$ depression predominates. This is consistent with the observation that in some experiments, in normal saline, the second EJP in a train was actually larger than the first. In other preparations, such as the squid giant synapse, a similar change from depression to facilitation is obscrved when $\left[\mathrm{Ca}^{2+}\right]_{o}$ is lowercd (Swandulla et al., 1991). The loss of depression under conditions of lowered probability of release precluded doing a quantal analysis of depression (Castellucci and Kandel, 1974; Larkman et al., 1991). Future experiments will utilize focal recordings of synaptic currents to perform a quantal analysis.

The synaptic depression at gm9 synapses could be due to depletion of neurotransmitter as has been proposed for depression at other synapses (Thies, 1965; Betz, 1970; Schlapfer et al., 1974; Czternasty and Bruner, 1980; Gingrich and Byrne, 1985). When release is reduced by decreasing calcium influx, then less 
transmitter is depleted and there is consequently less depression. Changes in $\mathrm{Ca}^{2+}$ influx do not affect depression at the neuromuscular junctions made by the crayfish "giant" abdominal motor neuron (Zucker and Bruner, 1977), at the neuromuscular' terminals of the crab walking leg that exhibit "low-frequency" depression (Bryan and Atwood, 1981), or at Aplysia sensory neuron synapses (Castellucci and Kandel, 1974). In these systems, depletion of neurotransmitter is not believed to play a role in synaptic depression. However, in crab walking leg neuromuscular junctions that exhibit "high-frequency" depression, decreasing $\mathrm{Ca}^{2+}$ influx decreases depression. In these latter synapses, loss of synaptic vesicles accompanies depression, indicating a depletion of ncurotransmitter (Bryan and Atwood, 1981). Our results do not rule out other calcium-dependent presynaptic mechanisms for depression.

The lack of a decrease in depression under conditions where the postsynaptic receptors were blocked or desensitized supports a presynaptic locus for the depression at gm 9 synapses. In particular, it shows that a postsynaptic mechanism involving calcium entry or depolarization is probably not involved in depression.

In some experiments a reduction of EJP amplitude through partial receptor desensitization or partial receptor blockade caused a slight increase in depression. It is possible that bathapplied glutamate affects release of transmitter through action on presynaptic glutamate receptors. However, this is unlikely since JSTX had the same effect as bath-applied glutamate but does not appear to affect presynaptic glutamate receptors in lobsters (Miwa et al., 1990). The increase in depression with altered postsynaptic sensitivity is still consistent with a presynaptic locus for the depression. If two or more glutamate molecules are required to open a channel, then a reduction in the density of receptors through desensitization or blockade, would have a nonlinear effect on the synaptic current evoked by decreasing amounts of transmitter. That is, when transmitter release is lowered during depression, there will be a decreased likelihood that two transmitter molecules will bind at a given receptor and this will result in proportionally more depression than if the density of receptors were higher (Bartol et al., 1991).

\section{Correlation between physiology and fine structure}

At low stimulus frequencies, EJPs evoked in gm9 are much larger than those in gm8. Possible mechanisms for this difference in the size of the EJPs include differences in the amount of transmitter released at the two terminals, differences in the density of receptors on the postsynaptic membranes of the two muscles, or a combination of both. The difference in the evoked synaptic current is likely to be even greater than the difference in EJP amplitude because the input resistance of the gm 9 muscle fibers is less than one-third that of the gm 8 fibers. Thus, assuming that the muscle acts as a linear RC circuit, a synaptic current would have to be $15 \times$ larger in gm9 to produce a synaptic potential that is $5 \times$ larger than that in $\mathrm{gm} 8$. The ratio of synaptic strengths that were needed to model the EJPs supports this contention; the synaptic strength of the gm 9 model synapse was $13.5 \times$ larger than that of the gm 8 model synapse (see "Syn," Fig. $8 C, F$ ).

The fine structure of the neuromuscular innervation formed by the MG axon on the two separate muscles, gm8 and gm9, although not qualitatively different, appears to differ in some important quantitative aspccts. Synapscs on gm 9 arc larger than their counterparts on gm8 and have on average more dense bars, which have been correlated with active sites of transmitter release (Govind and Chiang, 1979; Govind et al., 1982; Atwood and Marin, 1983; Pearce et al., 1986). Consequently, gm9 synapses may initially generate greater output of transmitter. While this is a positive correlation, the differences in synapse size or density of bars are certainly not large enough to account for the difference in synaptic current at the two muscles. Part of the discrepancy may be due to differences in receptor density on the postsynaptic membrane.

Our data suggest a nonlinear relationship between synapse size and number of dense bars, and transmitter output. A similar deduction was made for muscle fibers with high- and low-output synapses, which differed in either the number (Govind and Chiang, 1979), size (Atwood and Marin, 1983), or both the number and size (Govind and Meiss, 1979) of active sites. Membrane fractures along presynaptic active sites reveal large intramembrane particles representing putative calcium channels (Pearce et al., 1986), and since a fourth-power relationship has been implicated between calcium and transmitter output (Augustine and Charlton, 1986), the nonlinear correlation between presynaptic dense bars (putative active sites) and transmitter output in the present study is not unexpected.

It is also possible that the proximity of the active sites to one another may play a cooperative role in enhancing the calcium concentration during release. Twenty-seven percent of the gm 9 synapses had three or more dense bars, an unusually high percentage even for high-output synapses (Atwood et al., 1978; Govind and Chiang, 1979; Govind and Meiss, 1979). This clustering of active zones and their associated calcium channels might result in such a large local calcium influx as to overwhelm momentarily the calcium-buffering capacity of the terminal. This would lead to a larger release of transmitter than if the active zones were more separated. The enhanced release might be responsible for depression at the gm 9 synapses because of consequent transmitter depletion. When calcium influx is lowered through blockade of calcium channels or reduction of extracellular calcium, the amount of release is lowered and the amount of depression decreases. When calcium is lowered sufficiently, the EJPs in gm9 show facilitation instead of depression. Under these conditions, calcium is now a limiting factor in release and residual calcium buildup could result in facilitation.

In contrast to gm 9 where all of the synapses have at least one dense bar, almost $20 \%$ of the gm 8 synapses lacked them entirely. This suggests that a large number of potential synapses could be inactive (Atwood et al., 1978; Govind and Chiang, 1979; Govind and Meiss, 1979) and these synapses may become active if the motor neuron fired repetitively (Mearow and Govind, 1989; Wojtowicz et al., 1991), such as would occur during a prolonged bout of gastric mill activity.

These data indicate that the basis for the differentiation of the MG terminals on the gm 8 and gm 9 muscles could be the clustering of active sites. Many, if not all, of the physiological properties of the gm 9 synapses could result as a consequence of this structural feature. A future test of this hypothesis would be to measure calcium influx at the terminals to show that there is a greater influx at $\mathrm{gm} 9$ synapses than at $\mathrm{gm} 8$.

Another unanswered question is how differentiation of synaptic terminals from a single motor neuron on these two muscles occurs during development. In another lobster neuromuscular system, the muscle has been implicated in determining the physiology of synapses that contact it (Frank, 1973). In the leech, contact with peripheral target tissue causes morphological dif- 
ferentiation of segmentally homologous neurons (Loer et al., 1987; French and Kristan, 1992). In crickets, contact with a novel postsynaptic target causes neurons that normally exhibit facilitation to display synaptic depression (Killian and Murphey, 1992). Thus, it is possible that contact with the target muscle specifies the divergent properties of the $\operatorname{gm} 8$ and $\operatorname{gm} 9$ synaptic terminals.

\section{Postsynaptic differences contribute to the behavior}

While we focused on depression of transmitter release as the primary difference between the muscles, there are postsynaptic properties that amplify the effect of differential presynaptic relcasc. For cxamplc, the gm 8 muscle has a higher input resistance. Correspondingly, the time constant is longer, and likely results in the broader gm 8 EJPs that summate at lower stimulus frequencies. In contrast, EJPs in gm 9 do not summate until frequencies above $10 \mathrm{~Hz}$ where there is considerable depression.

The structure of the two muscles also differs. The gm 8 muscle is more similar to a crustacean slow muscle, while the gm9 muscle has properties of a crustacean fast muscle. These differing properties, which include differences in sarcomere length, thinto-thick filament ratio, and dyad location, are important for determining the strength and speed of contraction. The longer sarcomere length of gm 8 is consistent with observations in other crustacean muscles that input resistance is greater in fibers with longer sarcomeres (Sherman and Atwood, 1972).

A further difference is seen in the active properties of the muscles. The gm 9 muscle sometimes exhibits an active response atop the first, undepressed EJP. This response accentuates the amount of depression by increasing the initial depolarization during a train.

The crab Callinectes sapidus has muscles that are homologous to $\mathrm{gm} 8$ and $\mathrm{gm} 9$ and are innervated by the homolog of $\mathrm{MG}$ (Maynard and Dando, 1974; Govind et al., 1975). The EJPs in these muscles differ from each other in the extent of facilitation, but neither muscle displays synaptic depression (Govind et al., 1975; Jahromi and Govind, 1976; Atwood et al., 1977). In contrast to the situation in lobster, the two crab muscles are not very different in sarcomere length and the thin-to-thick myofilament ratio is reversed in the crab; gm9 has a ratio (6:1) higher than gm8 (3:1). These differences may be related to differences in the anatomy of the foregut in crab; in crabs, the gm 9 muscle is much smaller and the gm 8 muscle is larger. This divergence in muscle structure may indicate that the functions of these muscles are different in the two species.

\section{Consequences for behavior}

The gm8, gm6a, and gm5b muscles are synergists involved in closing the lateral teeth of the gastric mill that are used to masticate food after it is ingested. The gm 9 muscle group controls a series of brushes and pads located on the interior of the foregut beneath the muscle, which form the lateral cardiopyloric valve (Hinton and Corey, 1979). Contraction of gm 9 causes these pads to close, constricting the entrance to the dorsal pyloric channel. Movement of the lateral cardiopyloric valve may also be involved in the circulation of liquids and solids in the cardiac sac.

The differences in facilitation and depression properties of the two terminals combined with the differences in EJP shape, result in a peripherally determined sequence of movements. The MG motor neuron is part of the gastric mill central pattern generator and thus fires bursts of action potentials lasting from 2 to $7 \mathrm{sec}$ with a periodicity of $10 \mathrm{sec}$ or more (Mulloney and
Selverston, 1974; Selverston, 1987). Each time that the motor neuron fires in this repetitive pattern, the gm 8 and $\mathrm{gm} 9$ muscles respond in the following way: the gm 9 muscle immediately contracts and then relaxes, momentarily closing the lateral cardiopyloric valve. This is followed by a slow contraction of the gm8 muscle, closing the lateral teeth after the valve has reopened. This sequence of events could not be predicted by observing only the motor neuron firing pattern because it is shaped by the different properties of the two sets of neuromuscular terminals. The different activity-dependent properties of the gm8 and gm9 terminals may also function to cause differential activation of the muscles during the production of alternate motor patterns, such as when MG fircs in phase with the faster pyloric motor pattern (Katz and Harris-Warrick, 1991; Weimann et al., 1991). Other muscles in the stomatogastric system have been shown to display complex neuromuscular properties that allow separate activation of muscles innervated by a single motor neuron (Meyrand et al., 1992).

\section{Comparison with other systems}

In crustaceans, differentiation of neuromuscular synapses from a single motor neuron has been recorded usually among different regions of a single muscle, such as in the lobster limb accessory flexor muscle where high- and low-output excitatory synapses occur on distal and proximal bundles, respectively (Govind and Walrond, 1989). The single excitor motor neuron to the crayfish limb opener muscle gives rise to high-output synapses on the proximal part and to low-output ones on the central part (Atwood and Wojtowicz, 1986). Although the functional significance of such regionalization in synaptic performance is not known, synaptic differentiation in these muscles with a single excitor motor neuron serves to extend their functional range as the degree of contraction of crustacean muscle fibers is depolarization dependent (Atwood and Dorai Raj, 1964; Atwood, $1976,1982)$. In the present case, even though they are innervated by a common motor neuron, gm 8 and gm 9 can perform separate functions as a consequence of the synaptic differentiation described here.

Central synapses of a single neuron can also exhibit differences in activity-dependent processes. In the cat, single Ia afferents make facilitating and depressing synapses onto different motor neurons (Koerber and Mendell, 1991). A similar situation occurs in the crab, where the synapses made by a sensory neuron depress on one motor neuron but not the other (Katz and HarrisWarrick, 1989, 1991). It is not known if presynaptic differences play a role in the divergent responses in these two examples. In the cricket, quantal analysis has shown that a single sensory neuron exhibits presynaptic differences in release that cause facilitation at one central synapse and depression at another (Davis and Murphey, 1992, in press). Presynaptic differences in quantal release at different terminals of a single neuron have also been observed in other insects and in mollusks (Gardner, 1991; Laurent and Sivaramakrishnan, 1992). Thus, neurons can have different activity-dependent processes occurring at different synaptic terminals. This has important significance for neuronal computation since neurons with these properties are capable of great flexibility in local information processing.

\section{References}

Atwood HL (1967) Variation in physiological properties of crustacean motor synapses. Nature 215:57-58. 
Atwood HL (1976) Organization and synaptic physiology of crustacean neuromuscular systems. Prog Neurobiol 7:291-391.

Atwood HL (1982) Synapses and neurotransmitters. In: The biology of Crustacea, Vol 3, Neurobiology: structure and function (Bliss DE, Atwood HL, Sandeman DC, eds), pp 105-150. New York: Academic.

Atwood HL, Dorai Raj BS (1964) Tension development and membranc responses in phasic and tonic muscle fibers of a crab. J Cell Comp Physiol 64:55-72.

Atwood HL, Marin L (1983) Ultrastructure of synapses with different transmitter-releasing characteristics on motor axon terminals of a crab, Hyas areneas. Cell Tissue Res 231:103-115.

Atwood HL, Wojtowicz JM (1986) Short-term and long-term plasticity and physiological differentiation of crustacean motor synapses. Int Rev Neurobiol 28:275-361.

Atwood HL, Govind CK, Jahromi SS (1977) Excitatory synapses of blue crab gastric mill muscles. Cell Tissue Res 177:145-158.

Atwood HL, Govind CK, Kwan I (1978) Non-homogenous excitatory synapses of a crab stomach muscle. J Neurobiol 9:17-28.

Augustine GJ, Charlton MP (1986) Calcium dependence of presynaptic calcium current and postsynaptic response at the squid giant synapse. J Physiol (Lond) 382:619-640.

Bartol TM Jr, Land BR, Salpeter EE, Salpeter MM (1991) Monte Carlo simulation of miniature endplate current generation in the vertebrate neuromuscular junction. Biophys J 59:1290-1307.

Betz WJ (1970) Depression of the transmitter release at the neuromuscular junction of the frog. J Physiol (Lond) 206:629-644.

Bittner GD (1968) Differentiation of nerve terminals in the crayfish opener muscle and its functional significance. J Gen Physiol 51:731758.

Bryan JS, Atwood HL (1981) Two types of synaptic depression at synapses of a single crustacean motor axon. Mar Behav Physiol 8:99121.

Byrne JH (1982) Analysis of synaptic depression contributing to habituation of gill-withdrawal reflex in Aplysia californica. J Neurophysiol 48:431-438.

Castellucci VF, Kandel ER (1974) A quantal analysis of the synaptic depression underlying habituation of the gill-withdrawal reflex in Aplysia. Proc Natl Acad Sci USA 71:5004-5008.

Czternasty G, Bruner J (1980) On the mechanism of a long-lasting neuromuscular depression in crayfish. Comp Biochem Physiol [C] 66: 143-148.

Czternasty G, Bruner J, Galeano C (1980) Role of long-lasting neuromuscular depression in muscle activity in crayfish. Comp Biochem Physiol [C] 66:137-142.

Davis GW, Murphey RK (1992) Retrograde determination of presynaptic plasticity: quantal analysis at a central synapse. Soc Neurosci Abstr 18:791.

Davis GW, Murphey RK (in press) A role for postsynaptic neurons in determining presynaptic release properties in the cricket CNS: evidence for retrograde control of facilitation. J Neurosci, in press.

Delaney K, Tank DW, Zucker RS (1991) Presynaptic calcium and serotonin-mediated enhancement of transmitter release at crayfish neuromuscular junction. J Neurosci 11:2631-2643.

Dudel J (1989) Calcium and depolarization dependence of twin-pulse facilitation of synaptic release at nerve terminals of crayfish and frog muscle. Pfluegers Arch 415:304-309.

Frank E (1973) Matching of facilitation at the neuromuscular junction of the lobster: a possible case for the infiuence of muscle on nerve. $J$ Physiol (Lond) 233:635-658.

French KA, Kristan WB Jr (1992) Target influences on the development of leech neurons. Trends Neurosci 15:169-174.

Gardner D (1991) Presynaptic transmitter release is specified by postsynaptic neurons of Aplysia buccal ganglion. J Neurophysiol 66:21502154.

Gardner D, Kandel ER (1977) Physiological and kinetic properties of cholinergic receptors activated by multiaction interneurons in buccal ganglia of Aplysia. J Neurophysiol 40:333-348.

Getting PA (1989) Reconstruction of small neural networks. In: Methods in neuronal modeling: from synapses to networks (Koch C, Segev I, eds), pp 171-194. Cambridge, MA: MIT Press.

Gingrich KJ, Byrne JH (1985) Simulation of synaptic depression, posttetanic potentiation, and presynaptic facilitation of synaptic potentials from sensory neurons mediating gill-withdrawal reflex in Aplysia. J Neurophysiol 53:652-669.

Govind CK, Chiang RG (1979) Correlation between presynaptic dense bodies and transmitter output at lobster neuromuscular terminals by serial section electron microscopy. Brain Res 161:377-388.

Govind CK, Lingle CJ (1987) Neuromuscular organization and pharmacology. In: The crustacean stomatogastric system (Selverston AI, Moulins M, eds), pp 31-48. Berlin: Springer.

Govind CK, Meiss DE (1979) Quantitative comparison of low- and high-output neuromuscular synapses from a motoneuron of the lobster (Homarus americanus). Cell Tissue Res 198:455-463.

Govind CK, Pearce J (1982) Proliferation and relocation of developing lobster neuromuscular synapses. Dev Biol 90:67-68.

Govind CK, Walrond JM (1989) Structural plasticity at crustacean neuromuscular synapses. J Neurobiol 20:409-421.

Govind CK, Atwood HL, Maynard DM (1975) Innervation and neuromuscular physiology of intrinsic foregut muscles in the blue crab and spiny lobster. J Comp Physiol [A] 96:185-204.

Govind CK, Meiss DE, Pearce J (1982) Differentiation of identifiable lobster neuromuscular synapses during development. J Neurocytol 11:235-247.

Hatt H, Smith DO (1976) Synaptic depression related to presynaptic axon conduction block. J Physiol (Lond) 259:367-393.

Herrick FH (1895) The American lobster: a study of its habits and development. Bull US Fish Comm 15:1-252.

Hinton DJ, Corey S (1979) The mouthparts and digestive tract in the larval stages of Homarus americanus. Can J Zool 57:1413-1423.

Hochner B, Parnas H, Parnas I (1991) Effects of intra-axonal injection of $\mathrm{Ca}^{2+}$ buffers on evoked release and on facilitation in the crayfish neuromuscular junction. Neurosci Lett 125:215-218.

Jahromi SS, Govind CK (1976) Ultrastructural diversity in motor units of crustacean stomach muscles. Cell Tissue Res 166:159-166.

Katz B, Miledi R (1967) A study of synaptic transmission in the absence of nerve impulses. J Physiol (Lond) 192:407-436.

Kat7. B, Miledi R (1968) The role of calcium in neuromuscular facilitation. J Physiol (Lond) 195:481-492.

Katz PS, Harris-Warrick RM (1989) Serotonergic/cholinergic muscle receptor cells in the crab stomatogastric nervous system. II. Rapid nicotinic and prolonged modulatory effects on neurons in the stomatogastric ganglion. J Neurophysiol 62:571-581.

Kat $\angle$ PS, Harris-Warrick RM (1991) Recruitment of crab gastric mill neurons into the pyloric motor pattern by mechanosensory afferent stimulation. J Neurophysiol 65:1442-1451.

Kawai N, Miwa A, Shimazaki K, Sahara Y, Robinson HPC, Nakajima $\mathrm{T}$ (1991) Spider toxin and the glutamate receptors. Comp Biochem Physiol [C] 98C:87-95.

Killian KA, Murphey RK (1992) Retrograde control of facilitation at an ectopic central synapse. Soc Neurosci Abstr 18:581.

Koerber RH, Mendell LM (1991) Modulation of synaptic transmission at Ia-afferent fiber connections on motor neurons during high-frequency stimulation: role of the postsynaptic target. J Neurophysiol 65:590-597.

Kusano K, Landau EM (1975) Depression and recovery of transmission at the squid giant synapse. J Physiol (Lond) 245:13-32.

Lang F (1975) A simple culture system for juvenile lobsters. Aquaculture 6:389-393.

Larkman A, Stratford K, Jack I (1991) Quantal analysis of excitatory synaptic action and depression in hippocampal slices. Nature 350: 344-347.

Laurent G, Sivaramakrishnan A (1992) Single local interneurons in the locust make central synapses with different properties of transmitter release on distinct postsynaptic neurons. J Neurosci 12:2370 2380 .

Liley AW, North KAK (1953) An electrical investigation of effects of repetitive stimulation on the mammalian neuromuscular junction. $\mathrm{J}$ Neurophysiol 16:509-527.

Lingle C (1980) The sensitivity of decapod foregut muscles to acetylcholine and glutamate. J Comp Physiol [A] 138:187-199.

Loer CM, Jellies J, Kristan WB Jr (1987) Segment-specific morphogenesis of leech Retzius neurons requires particular peripheral targets. J Neurosci 7:2630-2638.

Marder E (1987) Neurotransmitters and neuromodulators. In: The crustacean stomatogastric system (Selverston AI, Moulins M, eds), pp 263-300. Berlin: Springer.

Maynard DM, Dando MR (1974) The structure of the stomatogastric neuromuscular system in Callinectes sapidus, Homarus americanus and Panulirus argus (Decapoda Crustacea). Philos Trans R Soc Lond [Biol] 268:161-220. 
Mearow KM, Govind CK (1989) Stimulation induced changes at crayfish (Procambarus clarkii) neuromuscular terminals. Cell Tissue Res 256:119-123.

Meyrand P, Weimann JM, Marder E (1992) Multiple spike initiation zones in a motor neuron: serotonin activation. J Neurosci 12:28032812.

Miwa A, Michio U, Kawai N (1990) G protein is coupled to presynaptic glutamate and GABA receptors in lobster neuromuscular synapse. J Neurophysiol 63:173-180.

Moczydlowski E, Lucchesi K, Ravindran A (1988) An emerging pharmacology of peptide toxins targeted against potassium channels. $J$ Membr Biol 105:95-111.

Mulloney B, Selverston AI (1974) Organization of the stomatogastric ganglion of the spiny lobster. I. Neurons driving the lateral teeth. $\mathbf{J}$ Comp Physiol 91:1-32.

Pearce J, Govind CK, Shivers RR (1986) Intramembranous organization of lobster excitatory neuromuscular synapses. J Neurocytol 15: 241-252.

Pcrkel DH, Mulloney B, Budelli RW (1981) Quantitative methods for predicting neuronal behavior. Neuroscience 6:823-837.

Sarrazin C (1987) Underlying mechanisms of facilitation and depression of transmitter release. The role of calcium in synaptic transmission. Neurol Res 9:249-258.

Schlapfer WT, Woodson PBJ, Tremblay JP, Barondes SH (1974) Depression and frequency facilitation at a synapse in Aplysia californica: evidence for regulation by availability of transmitter. Brain Res 76: 267-280.

Selverston AI (1987) Gastric mill mechanisms. In: The crustacean stomatogastric system (Stevenson AI, Moulins M, eds), pp 147-171. Berlin: Springer.

Sherman RG, Atwood HL (1972) Correlated electrophysiological and ultrastructural studies of a crustacean motor unit. J Gen Physiol 59: 586-615.
Swandulla D, Hans M, Zipser K, Augustine GJ (1991) Role of residual calcium in synaptic depression and posttetanic potentiation: fast and slow calcium signaling in nerve terminals. Neuron 7:915-926.

Thies RE (1965) Neuromuscular depression and the apparent depletion of transmitter in mammalian muscle. J Neurophysiol 28:427442.

Weimann JM, Meyrand P, Marder E (1991) Neurons that form multiple pattern generators: identification and multiple activity patterns of gastric/pyloric neurons in the crab stomatogastric system. J Neurophysiol 65:111-122.

Wiersma CAG (1961) The neuromuscular system. In: The physiology of Crustacea, Vol II (Waterman TH, ed), pp 191-240. New York: Academic.

Wine JJ, Krasne FB (1982) The cellular organization of escape behavior. In: The biology of Crustacea, Vol 4, Neural integration and behavior (Bliss DE, Sandeman DC, Atwond HL, eds), pp 231-292. New York: Academic.

Wojtowicz JM, Smith BR, Atwood HL (1991) Activity-dependent recruitment of silent synapses. Ann NY Acad Sci 627:169-179.

Zucker RS (1972) Crayfish escape behavior and central synapses. II Physiological mechanisms underlying behavioral habituation. J Neurophysiol 35:621-637.

Zucker RS (1974) Characteristics of crayfish neuromuscular facilitation and their $\mathrm{Ca}^{++}$dependence. J Physiol (Lond) 241:91-110.

Zucker RS (1989) Short-term synaptic plasticity. Annu Rev Neurosci 12:13-31.

Zucker RS, Bruner J (1977) Long-lasting depression and the depletion hypothesis at crayfish neuromuscular junctions. J Comp Physiol [A] 121:223-240.

7ucker RS, Delaney KR, Mulkey R, Tank DW (1991) Presynaptic calcium in transmitter release and posttetanic potentiation. Ann NY Acad Sci 635:191-207. 